\title{
The Wonder Years: What Can Primary School Children Teach Us About Immunity to Mycobacterium tuberculosis?
}

\begin{abstract}
James A. Seddon ${ }^{1,2 *}$, Silvia S. Chiang ${ }^{3,4}$, Hanif Esmail ${ }^{5,6}$ and Anna K. Coussens ${ }^{6,7,8,9}$
${ }^{1}$ Department of Paediatrics, Imperial College London, London, United Kingdom, ${ }^{2}$ Desmond Tutu TB Centre, Department of Paediatrics and Child Health, Faculty of Medicine and Health Sciences, Stellenbosch University, Cape Town, South Africa, ${ }^{3}$ Department of Pediatrics, Warren Alpert Medical School of Brown University, Providence, Rl, United States, ${ }^{4}$ Center for International Health Research, Rhode Island Hospital, Providence, RI, United States, ${ }^{5}$ Radcliffe Department of Medicine, University of Oxford, Oxford, United Kingdom, ${ }^{6}$ Wellcome Centre for Infectious Diseases Research in Africa, Institute of Infectious Disease and Molecular Medicine, University of Cape Town, Cape Town, South Africa, ${ }^{7}$ Infection and Immunity Division, Walter and Eliza Hall Institute of Medical Research, Parkville, VIC, Australia, ${ }^{8}$ Division of Medical Biology, Faculty of Medicine, Dentistry and Health Sciences, University of Melbourne, Parkville, VIC, Australia, ${ }^{9}$ Division of Medical Microbiology, Department of Pathology, University of Cape Town, Cape Town, South Africa
\end{abstract}

In high burden settings, the risk of infection with Mycobacterium tuberculosis increases throughout childhood due to cumulative exposure. However, the risk of progressing from tuberculosis (TB) infection to disease varies by age. Young children ( $<5$ years) have high risk of disease progression following infection. The risk falls in primary school children ( 5 to $<10$ years), but rises again during puberty. TB disease phenotype also varies by age: generally, young children have intrathoracic lymph node disease or disseminated disease, while adolescents ( 10 to $<20$ years) have adult-type pulmonary disease. TB risk also exhibits a gender difference: compared to adolescent boys, adolescent girls have an earlier rise in disease progression risk and higher TB incidence until early adulthood. Understanding why primary school children, during what we term the "Wonder Years," have low TB risk has implications for vaccine development, therapeutic interventions, and diagnostics. To understand why this group is at low risk, we need a better comprehension of why younger children and adolescents have higher risks, and why risk varies by gender. Immunological response to $M$. tuberculosis is central to these issues. Host response at key stages in the immunopathological interaction with $M$. tuberculosis influences risk and disease phenotype. Cell numbers and function change dramatically with age and sexual maturation. Young children have poorly functioning innate cells and a Th2 skew. During the "Wonder Years," there is a lymphocyte predominance and a Th1 skew. During puberty, neutrophils become more central to host response, and CD4+ T cells increase in number. Sex hormones (dehydroepiandrosterone, adiponectin, leptin, oestradiol, progesterone, and testosterone) profoundly affect immunity. Compared to girls, boys have a stronger Th1 profile and increased numbers of CD8+ T cells and NK cells. Girls are more Th2-skewed and elicit more enhanced inflammatory responses. Non-immunological factors (including exposure intensity, behavior, and co-infections) 
may impact disease. However, given the consistent patterns seen across time and geography, these factors likely are less central. Strategies to protect children and adolescents from TB may need to differ by age and sex. Further work is required to better understand the contribution of age and sex to M. tuberculosis immunity.

Keywords: tuberculosis, children, adolescence, Mycobacterium tuberculosis, vaccination, infection, immunity, protection

\section{INTRODUCTION}

About a quarter of the global population (1), including nearly 70 million children and adolescents $<15$ years of age (2), is infected with Mycobacterium tuberculosis. Many infected individuals are able to contain $M$. tuberculosis without the organism ever causing pathology. However, in a subset, the intricate immunological response necessary to contain bacterial proliferation is lost. Of the nearly 70 million children and adolescents $<15$ years of age with TB infection, about 1 million develop TB disease each year (3). Young children, especially those $<2$ years of age, have an extremely high risk of developing $\mathrm{TB}$ disease after becoming infected. The risk then falls to a nadir in primary school children before rising during adolescence (4). In fact, the primary school years could be considered the "Wonder Years" of TB protective immunity: even when infected with $M$. tuberculosis, primary school children have the lowest risk, of any age throughout life, of progressing to TB disease.

Primary school children also have the most benign clinical manifestations of TB disease: classically, this age group has paucibacillary, intra-thoracic disease with greater involvement of the mediastinal lymph nodes than the lung parenchyma. Young children ( $<5$ years of age) also have this type of intrathoracic disease but are additionally at high risk of disseminated TB, which has a high mortality. Largely for this reason, of the nearly 250,000 individuals $<15$ years of age who die from TB each year, most are $<5$ years of age (5). Around the time of puberty, mediastinal lymph node disease and disseminated TB become uncommon. Pulmonary TB begins to present as destructive lesions of the lung parenchyma, frequently in the upper lobes and with cavitation (6-9); TB-related mortality rises again. Taken together, these observations suggest that primary school children are protected from the two extremes of TB disease: the disseminated pathology commoner in young children and the destructive pulmonary disease commoner in adolescents and adults (Figure 1). The first might be considered a failure of control of infection and the latter a failure to control disease, with primary school children possessing a balanced inflammatory response capable of both.

In this article, we present the data on age-related variations in TB progression risk and disease forms. Although no studies have directly examined the reasons for these age-based differences, we discuss possible underlying immunological mechanisms, in an attempt to garner a greater understanding of the immunological correlates of protective immunity which exist during the Wonder Years of childhood protection immunity. We will make the case that young children $<5$ years have deficiencies in the initial response to $M$. tuberculosis infection, which reduce the chance of successful containment of the organism. These deficiencies increase the risk of progression to disseminated disease. In contrast, adolescents develop an excessively inflammatory response in the early stages of disease, which leads to tissue damage and favors localized replication of M. tuberculosis. We will also highlight divergences in disease risk between adolescent boys and girls, and explore the possible impact of sex hormones on host response to M. tuberculosis. Finally, we discuss other potential factors underlying these ageand gender-associated differences in TB risk. Understanding why $\mathrm{TB}$ risk changes with age may provide insight into correlates of protection-which, in turn, may lead to the development of TB vaccines, immunomodulatory therapies, and diagnostic assays that utilize host immunological profiles.

\section{DEFINITIONS}

It is important to define key terms that will appear throughout this article. We use "infants" to refer to children $<12$ months of age. For the purposes of this article, "young children" refers to those who are $<5$ years of age and includes infants ( $<1$ year); "early childhood" is the corresponding time period. "Primary school children" are 5- to <10-year-olds, and "adolescents" are 10 - to $<20$-year-olds. Early adulthood refers to the third decade of life (10). Although stages of childhood encapsulate much more than chronological age, we use these definitions because most epidemiologic data are available in 5-year age bands. As puberty varies in age of onset, these definitions do not fully capture differences in physiological stages of development. Therefore, we also employ the terms "pre-pubescent," "pubescent," and "postpubescent" to differentiate children and adolescents with respect to their physical features.

Second, we apply the terms "sex" and "gender" according to their standard definitions. "Sex" refers to the physiological distinction associated with sex chromosomes, sex steroids, and reproductive organs. In contrast, "gender" comprises the social and cultural constructs of males and females, as well as one's self-identity (11). We do not consider intersex or transgender individuals in this article due to the lack of data on these groups. We have elected to use "gender" when reporting epidemiological data because of the influence of both physiology and social behavior on such measures.

Next, we differentiate "TB infection" and "TB disease." "TB infection," or " $M$. tuberculosis infection," refers to an asymptomatic state evidenced only by immune sensitization to M. tuberculosis, as diagnosed by a tuberculin skin test (TST) or interferon gamma release assay (IGRA). These tests are limited 


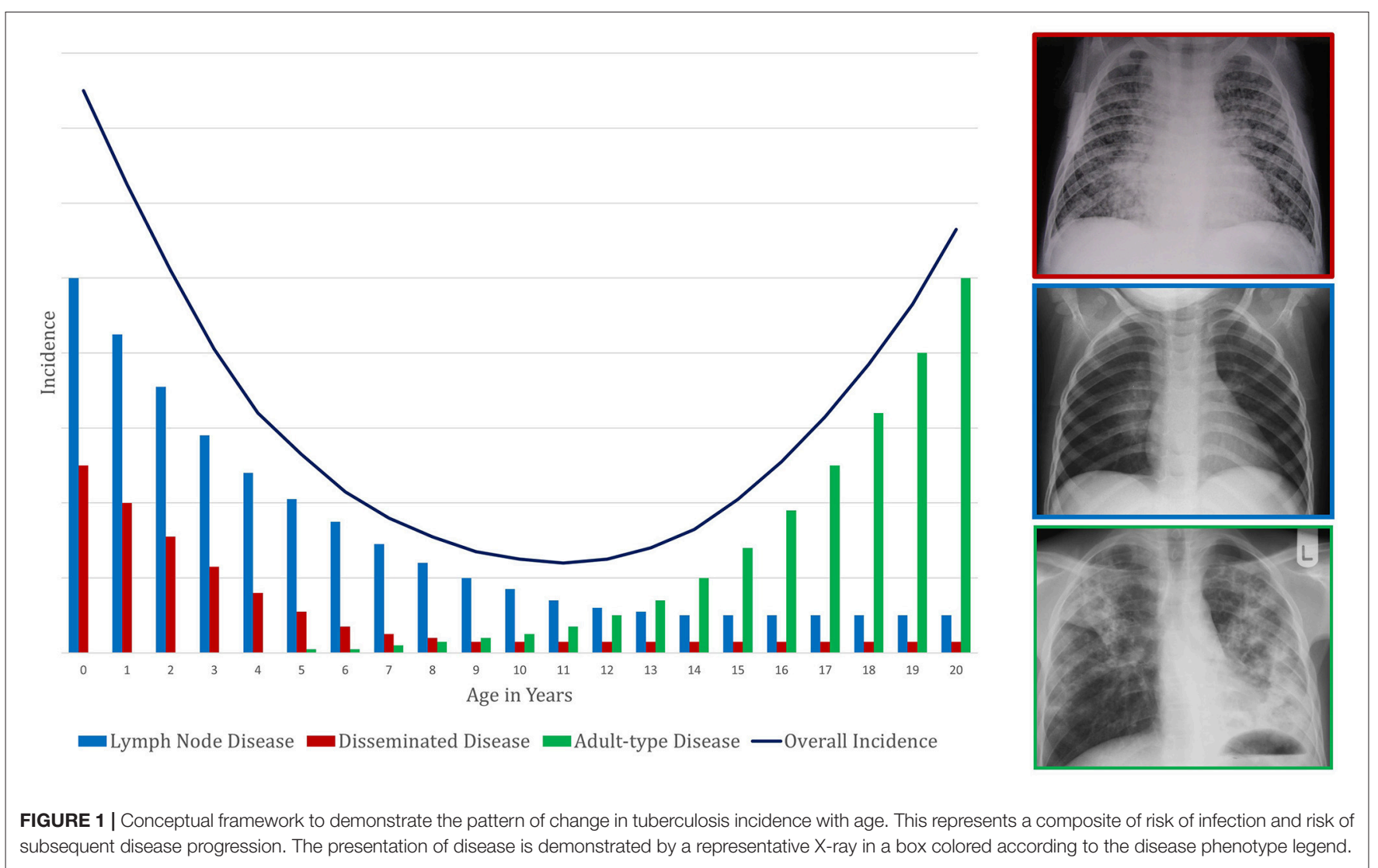

in not being able to distinguish the timing, nor current state, of infection. The most commonly used term for this state is "latent TB infection (LTBI)," but "LTBI" is a suboptimal term because it inaccurately implies both the metabolic dormancy of the mycobacteria and its persistence in the host (12). "TB disease" refers to the wide continuum of radiologically and/or clinically apparent abnormalities caused by the host response to M. tuberculosis. Just as "TB infection" often is called "LTBI," “TB disease" commonly is referred to as "active TB."

Finally, we define pathologically distinct clinical phenotypes of TB disease (Figure 1). "Intrathoracic lymph node TB" is generally paucibacillary and results due to spread from the site of the initial mycobacterial infection (the Ghon focus) to the regional lymph nodes. This manifestation historically was encompassed within "primary TB," a term now less commonly used. The "Ghon complex" is the name for the triad of the Ghon focus, surrounding lymphangitis, and regional intrathoracic lymphadenopathy. "Adult-type pulmonary TB" refers to disease that spreads bronchogenically within the lungs and may occur following prolonged initial control of infection. It typically initiates within the apico-posterior segments of the upper lobes or superior segment of the lower lobes; it appears as parenchymal infiltrates, often with cavitation, which facilitates contained expansion of bacillary numbers accompanying extracellular replication. Other terms for this clinical phenotype are "postprimary TB" and "reactivation TB," now less commonly in use. While $60 \%$ of adult $\mathrm{TB}$ is pulmonary, localized disease can occur in other organs and is termed "extra-pulmonary" TB.
"Disseminated TB," also known as "miliary TB," refers to the clinical manifestations of unrestrained haematogenous spread of mycobacteria $(13,14)$.

\section{CHANGES IN TUBERCULOSIS DISEASE PRESENTATION BY AGE}

As described above, age impacts the clinical phenotype of TB disease during childhood and adolescence (Figure 1). Prepubertal children, including both young children and primary school children, generally develop intrathoracic lymph node TB (15), which can have complications. If regional lymph nodes enlarge substantially, they can compress airways. If the node ulcerates into the bronchi and deposits caseous material into the airway, then inhalation will lead to dispersal of the mycobacteria throughout the portion of the lung supplied by that airway. This dispersal can lead to inflammation caused by acute hypersensitivity or segmental/lobar bronchopneumonic disease.

Young children, particularly those $<2$ years of age, also have a high risk of disseminated TB and/or TB meningitis. Disseminated TB can present with lung pathology (including the classic miliary picture seen on chest radiograph) and/or disseminated lesions throughout the body, including liver, spleen, gut, bone, and kidney. TB meningitis usually starts with an insidious clinical picture that rapidly progresses to neurological deficit. If untreated, both disseminated TB and TB meningitis almost universally lead to death $(16,17)$. During the primary 
school years, the risk of these disease forms is minimal. As children become older and approach puberty, they increasingly tend to develop adult-type pulmonary TB $(6,9,18-20)$. This clinical phenotype also leads to disease transmission (21).

\section{AGE-RELATED RISK OF TUBERCULOSIS PROGRESSION AND MORTALITY}

Our understanding of the impact of age on risk of progression from $\mathrm{TB}$ infection to disease comes from observational studies from the pre-chemotherapy era, many of which were summarized in a review by Marais et al. (4). This review included seven studies, which were conducted in Europe and North America after the advent of the TST and chest radiography, but prior to the discovery of anti-TB drugs and the HIV epidemic. The studies, which had a combined sample size of over 10,000 children and adolescents, evaluated the risk of progression to TB disease for TB-infected individuals of different ages. Table 1 summarizes these studies, as well as other relevant reports, including a trial of the Bacillus Calmette-Guérin (BCG) vaccine with over 82,000 TB-infected children and adolescents in the control arm (18).

The risks of disease progression described in these studies should be interpreted with caution. First, to define the age of acquisition of TB infection, some studies used baseline TST positivity and/or identification of the child or adolescent as a contact of a TB case (Table 1). Using these methods, it is difficult to establish when an individual was infected. Even if a source case is identified in the household and the child or adolescent screened soon thereafter, it is often unclear how long he or she had been exposed. It may also be unclear if the child or adolescent had prior exposure to another infectious TB case. Second, the TST has limited sensitivity and specificity to diagnose TB infection in young children. Third, the diagnosis of TB disease in children can be challenging. A clinical diagnosis can lack specificity due to the overlap in symptoms between TB and other conditions in children. Microbiological confirmation lacks sensitivity due to the paucibacillary nature of most forms of childhood TB disease, as well as the challenges in obtaining respiratory specimens from children. Finally, these studies were conducted in different settings, including wartime conditions, which likely impacted rates of progression to $\mathrm{TB}$ disease.

The widely varying risks of TB disease progression described in these studies reflect the limitations described above. Other reasons for the wide variation include the different quantities and varieties of tuberculin used across studies, as well as inconsistent definitions of TST positivity and TB disease. Additionally, the studies calculate risk of disease progression over different followup periods. Because risk of disease progression is greatest in the first year after acquisition of $M$. tuberculosis infection and then declines over time $(36,37)$, risks that are given per personyear inversely correlate with the length of follow-up. Not all the studies cited in Table 1 include risk of disease progression over the full spectrum of ages from infancy through late adolescence, and the studies use different age groupings. Nonetheless, as Table 1 illustrates, there is a general pattern of high risk during early childhood (particularly the first 2 years of life), a nadir during the primary school years or early adolescence (most likely occurring right before the onset of puberty), and a second peak during late adolescence. This overall picture reflects the different types of childhood TB, with falling rates of disseminated and lymph node TB in early childhood, superimposed on a rise in adult-type TB coinciding with puberty onset. Given that, in high burden settings, the risk of being infected with $M$. tuberculosis increases throughout childhood due to cumulative exposure (38), the resulting $\mathrm{TB}$ disease incidence seen in a community is a composite of risk of infection combined with risk of disease progression following infection. The TB incidence in high burden settings reflects the risk of disease progression, namely a $\mathrm{U}$ shaped pattern, only shifted a few years older so that the nadir is at about the age of 10 years (Figure 1).

The data in Table 1 show that mortality from TB disease follows the same pattern of age-related risk. Again, despite this consistent pattern, the rates themselves vary considerably, reflecting the different conditions in which the studies were conducted and the different denominators (e.g., whole populations of geographic areas vs. children and adolescents hospitalized for TB). A recent systematic review and metaanalysis that evaluated the risk of death in children and adolescents $<15$ years of age with TB disease found that mortality from untreated TB disease (in the pre-chemotherapy era) was $44 \%$ in children $<5$ years but only $15 \%$ in 5 to $<15$ year-olds. Mortality in individuals with TB who were diagnosed and treated was $<1 \%(39)$.

\section{DIFFERENCES IN TUBERCULOSIS RISK BY GENDER}

Although this article focuses on age-related differences in TB risk, it is worth noting that multiple studies have documented gender-based differences in TB risk, emerging coincident with the adolescent rise in TB risk and persists during adulthood. Overall, more males globally develop TB each year; compared to males, females tend to have higher risks of progression from $\mathrm{TB}$ infection to disease during adolescence. In a cohort of over 400,000 school children aged 6-19 years in Massachusetts, U.S.A., the incidence of TB disease among female TST reactors was approximately double that of male reactors (25). A TB vaccine trial that followed over 54,000 14- and 15-year-olds reported a $20 \%$ higher incidence of TB disease for girls than for boys (40). In a cohort of TB-infected children treated at Bellevue Hospital in New York City, twice as many girls as boys developed pulmonary infiltrates, and in more than a quarter of cases, adult-type pulmonary TB developed within a year of menarche (41). A study of over 82,000 children and adolescents in Puerto Rico, a trial of isoniazid prophylaxis in Alaskan Inuits, and an observational cohort in Ontario, Canada, all found that compared to males, females had higher rates of progression to TB disease in adolescence and early adulthood $(18,42,43)$.

Similar patterns have been observed with respect to mortality. From 1880 to 1930 in Massachusetts, girls between the ages of 10 and 20 years had nearly twice the risk of death from TB 


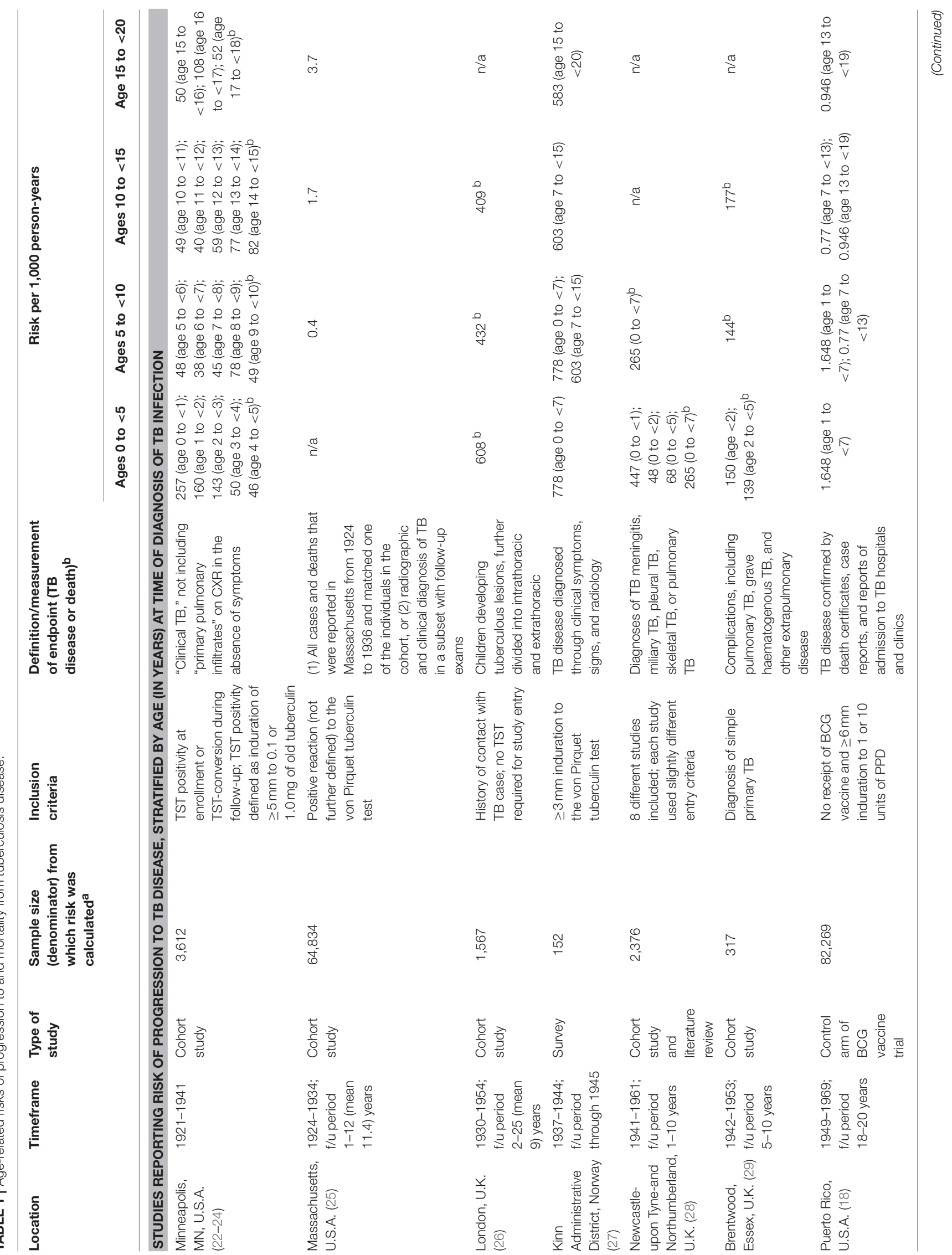




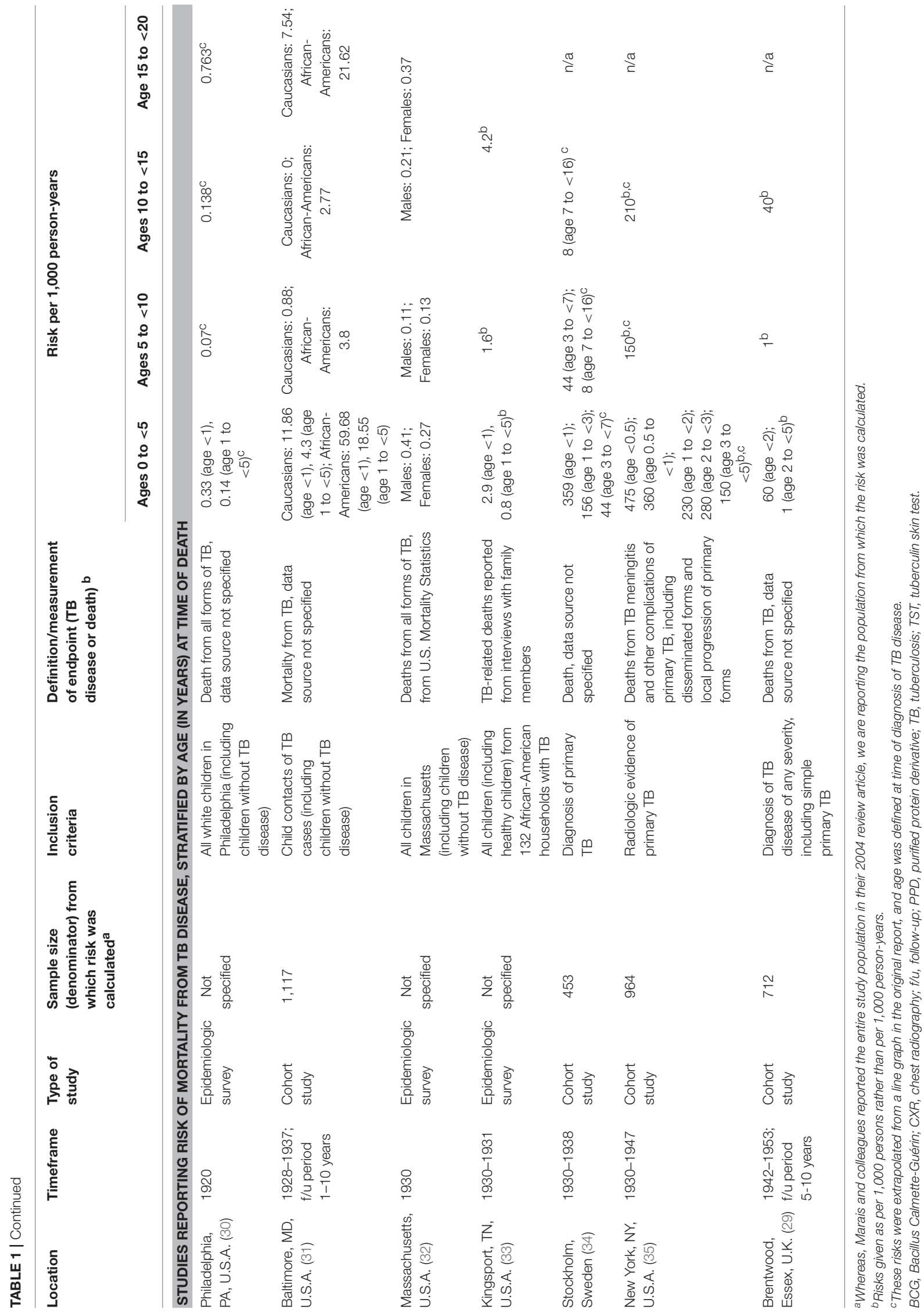


compared to boys in the same age range (32). More recent surveys conducted in India and China also showed that females during adolescence had higher rates of mortality due to TB than males (44).

It is difficult to establish whether these data reflect a greater risk of disease progression in post-pubertal females compared to post-pubertal males on an individual level, or whether females as a group have a greater risk of disease progression because they enter puberty sooner and, thus, have longer post-pubertal periods during adolescence.

\section{KEY STAGES IN THE IMMUNOPATHOLOGY OF TUBERCULOSIS}

There are a number of key stages in the host response to $M$. tuberculosis in humans, each governed by particular immune mechanisms, many of which remain incompletely understood. Age-related differences in risk and presentation may be explained by differences in the immune response at each of these key stages (Figure 2).

Exposure to infectious cases of TB can lead to inhalation of droplet nuclei containing viable $M$. tuberculosis. These infectious droplets may be cleared by the physical structures of the lung or by the innate immune system, but if they overcome these primary barriers and sensitize the adaptive component of the immune system without effective killing, the individual becomes infected with $M$. tuberculosis. Upon initial inhalation, bacilli are phagocytosed by the alveolar macrophage, which recruits neutrophils and other innate responders as a first line of defense. However, the ability of the innate immune response to control infection may be inhibited by bacterial-mediated mechanisms, particularly inhibition of phagolysosome fusion (the key bacterial killing mechanism of these phagocytes), resulting in persistence

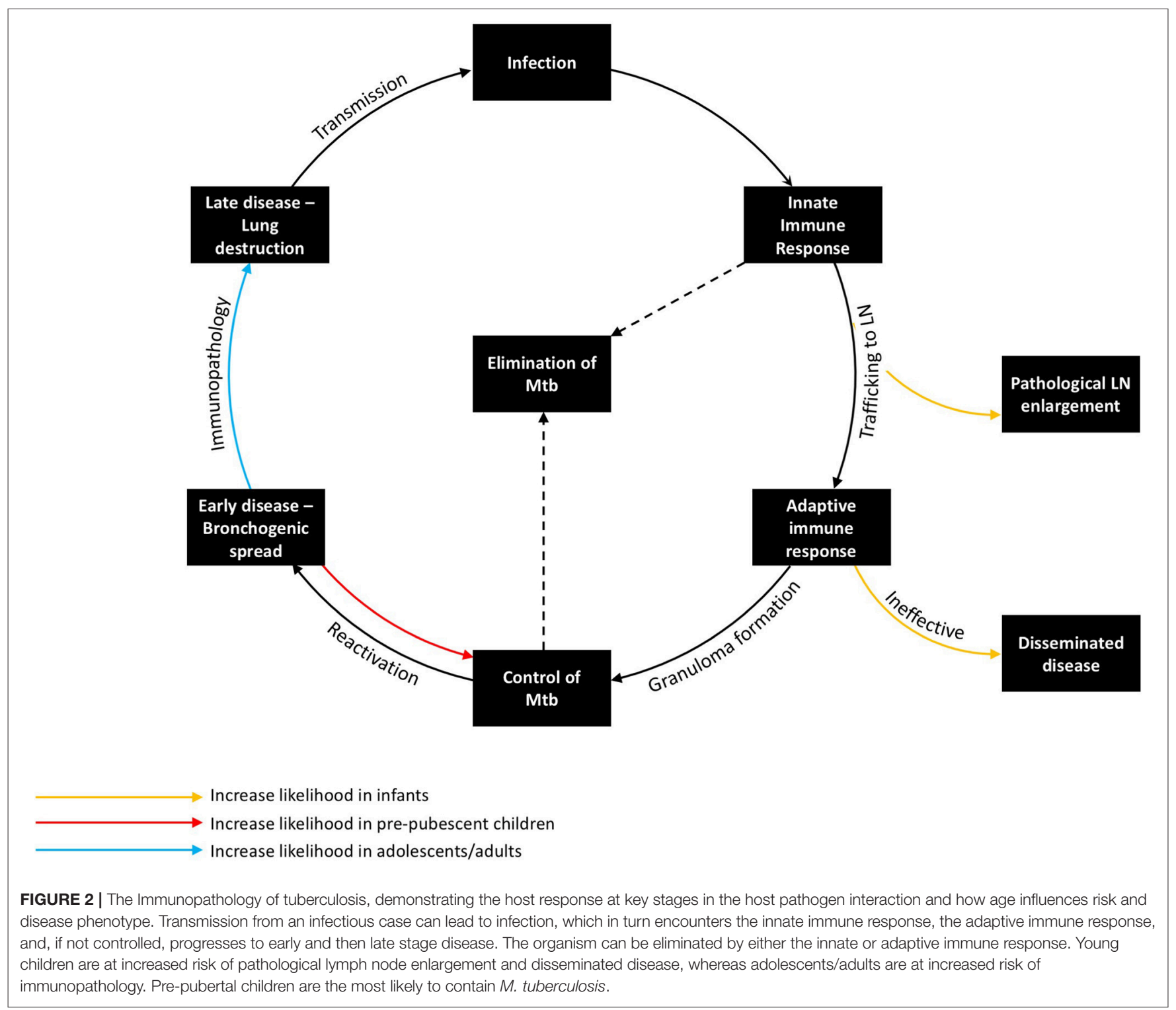


of bacilli intracellularly. It is during this period that initial antigen trafficking to the lymph nodes by dendritic cells (DCs) is felt to occur. The acquired immune response to $M$. tuberculosis usually develops 1-3 months after initial infection (as evidenced by TST or IGRA immune sensitization), with antigenspecific lymphocytes trafficking back into the lung, facilitating activation of macrophages and granuloma formation (45). At the center of the granuloma, macrophages may fuse together, forming multinucleated giant cells or differentiating into lipidrich foam cells $(46,47)$. Meanwhile, the neutrophils, which are short lived, undergo necrosis, contributing to a caseous center. This granulomatous response, if able to activate macrophages sufficiently to control bacterial replication, is thought to aid in containment of bacterial spread and reduce bacillary numbers, hence controlling or potentially eliminating $M$. tuberculosis.

Deficiencies in the antigen-specific Th1 immune response, which have been well-described in children $<2$ years-old, likely contribute to the presentation of locally progressive and disseminated TB in this age group $(48,49)$. BCG vaccination boosts mycobacterium-specific cell mediated immunity, which is associated with a reduced incidence of disseminated disease (50). Following early childhood, the initial granulomatous control of infection likely is effective (51). If infection is not eliminated by this stage, there is a risk of reactivation. Factors impeding effective T-cell-macrophage interaction within the granuloma increase the likelihood of disease progression. Some of these factors are well-known causes of systemic immunosuppression, such as HIV, malnutrition, and anti-tumor necrosis factor (TNF) therapy (12). While many of the factors that precipitate reactivation are poorly understood, seasonal changes in vitamin D levels or concurrent viral infection (e.g., influenza) may be involved (52, 53). Following failure of granulomatous control of $M$. tuberculosis, a pathologically distinct phase ensues in the lung. During this phase, which typically is characterized by a pneumonic process with bronchogenic spread, the number of organisms initially is low, although abundant antigen may be detected in uninfected cells and tissue (54). Progression of this early stage of reactivation TB is not linear; regression and self-healing of lesions are common (55). A critical event during this phase appears to be lung necrosis, which is likely caused by a number of pro-inflammatory mechanisms. Following lung necrosis, an increase in bacillary number is observed (55). Recently, necrotic cells themselves have been shown to be a niche for bacillary replication (56). Contributors to this inflammatory pathology may include immune complex deposition; complement activation; neutrophil recruitment; cell-mediated cytotoxicity directed against infected and uninfected antigen-containing cells; and tissue-degrading enzymes, which have the role of facilitating cell recruitment and vascularization, but result in the breakdown of tissue architecture (57-59). The late stage of adult-type disease is then characterized by lung destruction, cavitation, and a localized exponential growth of extracellular organisms that is most commonly seen in immunocompetent adults, who are the main contributors to $\mathrm{TB}$ transmission (21). The lower rate of disease seen in primary school children may relate to increased likelihood of a favorable outcome during the early stage of reactivation $\mathrm{TB}$, resulting in its resolution (Figure 2). It is possible that changes in the immune response that occur during puberty increase the likelihood of necrosis and disease progression.

\section{IMPACT OF AGE ON THE HOST RESPONSE TO M. tuberculosis}

To understand the potential mediators of protective immunity which exists during the pre-pubertal "Wonder Years," this unique age needs to be studied relative to the changes that occur as the immune system develops in infants and young children, and the further changes that occur during puberty. The primary driver of these developmental changes are sex hormones. Whilst the primary role of these hormones is development of reproductive organ function, they have wide-ranging effects on the immune system [for a detailed review see (60-62)]. Sex steroid receptors are found in the cytoplasm of the majority of immune cells, including T cells, B cells, DCs, natural killer (NK) cells, neutrophils, and macrophages (63). Once internalized in the cell, sex hormones bind their respective steroid receptors, inducing translocation to the nucleus and regulation of gene transcription via a variety of mechanisms. These mechanisms include direct binding to hormone response elements in DNA promoters to activate transcription; complexing with other transcription factors, such as AP-1, SP1, C/EBP $\beta$, and NFкB; or indirectly binding DNA via chromatin-modifying co-regulators $(64,65)$.

Multiple fluctuations in hormonal exposure occur throughout life, but the greatest changes occur during in utero development, puberty, and menopause (Figure 3). In utero, maintenance of foeto-maternal immune tolerance is critical to enable full term pregnancy. Fetal and maternal Th1 responses are harmful to the pregnancy and associated with pre-term labor and spontaneous abortion (66). High progesterone levels contribute to polarizing maternal and fetal immunity toward a more tolerant Th2 response $(67,68)$. The progesterone receptor $(\mathrm{PR})$ is expressed by NK, DC, macrophages, and T cells (69). Activation of PR (a) downregulates TNF, IL-1 $\beta$, IL-6, and IL-23 from DC (7072); (b) decreases microbial activity of macrophages as well as downregulating inducible nitric oxide synthase (iNOS) and nitric oxide (NO) production and polarizing macrophages to an M2 alternative-type (73); (c) decreases cytotoxicity and interferongamma $(\mathrm{IFN} \gamma)$ production from NK and CD8 cells $(62,74)$; and (d) increases expression of anti-inflammatory transcription factor FOXP3 in regulatory T cells (Tregs) and reducing IL-17 production (75). The high number of Tregs in the fetal circulation contribute to fetal tolerance of maternal alloantigen. This Th2 bias and increased number of peripheral Tregs persist into the neonatal period and affect responses to foreign antigen (49). This tolerant phenotype, along with the reduced antimicrobial activity and poor antigen presentation of innate immune cells, would be expected to contribute to impaired granulomatous control of intracellular M. tuberculosis infection in infants, resulting in high risks of disease progression and extrapulmonary dissemination (Figures 1, 2). 


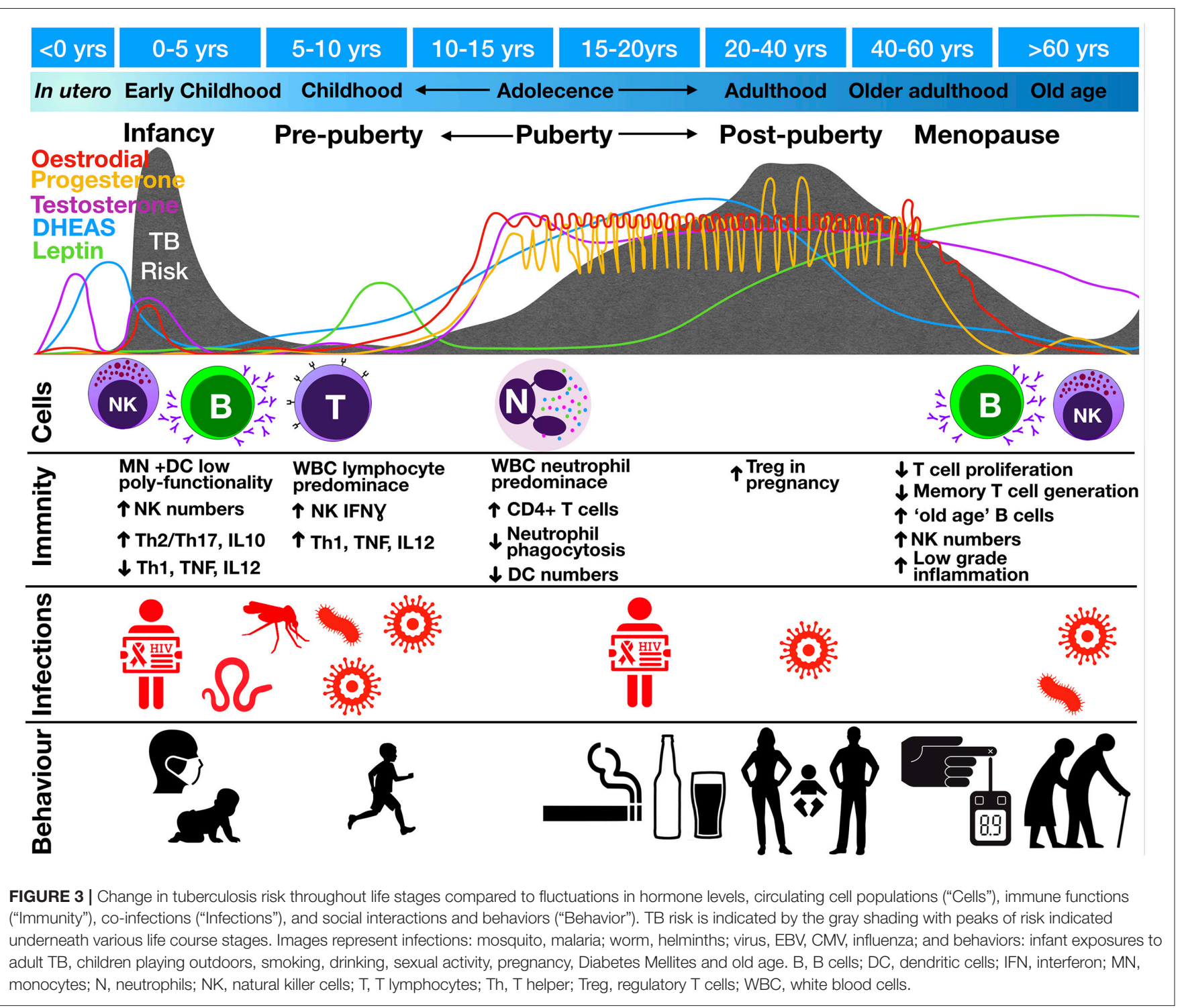

Whilst babies are born with an "underdeveloped" immune system due to low antigen exposure in utero, they experience rapid antigen exposure immediately following birth. During this period, both arms of the innate and adaptive immune system mature. Monocyte and DC maturation occurs during the 1st year of life (76), whilst NK cell function normalizes around the age of 5 years (77). NK cell function also changes as children progress into adolescence, switching from IFN $\gamma$-producing to more cytotoxic $(77,78)$. Infants have impaired type I IFN and Th1 (TNF, IFN $\gamma$, IL-12) responses and higher Th2/Th17 and IL-10 production (79). Early monocytes and DCs also show less polyfunctionality in cytokine production (80). This underdeveloped innate and adaptive immune system, with suboptimal innate cell-mediated killing and suppressed effector cell responses, is hypothesized to lead to poor outcome following M. tuberculosis infection, including widespread dissemination.

Puberty is defined by adrenarche and gonadarche, two temporally correlated but physiologically distinct events. Adrenarche, which begins around age 6 , is marked by the onset of production of dehydroepiandrosterone (DHEA), the primary adrenarche hormone, and its storage form, DHEAsulfate (DHEAS), hereafter collectively referred to as DHEA(S). $\operatorname{DHEA}(\mathrm{S})$, which leads to the development of axillary and pubic hair and sweat glands, is the most abundant steroid hormone in the body (81). In gonadarche, production of oestradiol or testosterone signals the maturation of reproductive organs and secondary sex characteristics. In addition, leptin-an adipocyteproduced hormone that regulates energy expenditure and signals the body is prepared for sexual maturation-increases at the onset of puberty (82).

In both sexes, the number of circulating leukocytes changes during the ages of 12-18 years, predominated by a drop in the high number of $\mathrm{B}$ cells found in young and primary school children and a rise in helper T lymphocytes (83). The functional requirement of these $\mathrm{T}$ cells for $\mathrm{TB}$ immunity was demonstrated in a recent study investigating the whole blood transcriptional signature of children and adolescents with pulmonary and extrapulmonary $\mathrm{TB}$. It identified a decline in $\mathrm{T}$ cell transcripts with 
increasing disease severity, with lower transcript levels found in those with TB meningitis compared to those with pulmonary TB. Moreover, this decline was associated with a functional defect in $\mathrm{T}$ cell proliferation following broad $\mathrm{T}$ cell receptor stimulation, which recovered after treatment (84).

The lymphocyte predominance seen in pre-pubertal years is overtaken by a predominance of neutrophils during adolescence and into adulthood (83), with neutrophils being considered a driver of cavitation and immunopathology in adult pulmonary TB (85). Early studies also show that the phagocytic capacity of neutrophils, at least to Staphylococcus aureus, decreases significantly during adolescence, with maximal kill peaking at 14 years of age (86). A decline in neutrophil phagocytic ability after the age of 14 would thereafter correspond to the rise in TB risk observed in late adolescence. The decreased phagocytic activity may be hypothesized to lead to increased necrosis and more tissue damage synonymous with adult pulmonary TB.

\section{IMPACT OF SEX ON THE HOST RESPONSE TO M. tuberculosis \\ Sex Differences in Inflammatory Responses}

In general, it is considered that of the sex hormones, oestrogens have immune-enhancing effects, such that the level of inflammatory response is generally higher in females, whilst progesterone and androgens, such as testosterone, exert mainly immunosuppressive properties (Table 2) (87). Moreover, males generally have a Th1 skewed response, and females, Th2 (63). Thus, females are thought to have a stronger innate and adaptive immune response, although overall skewed to a Th2 state (Figure 4) (89).

Androgens, including dihydrotestosterone (DHT) and testosterone, suppress Th2/Th17 responses and decrease antibody responses and B cell proliferation $(87,88,129,138)$. With regard to innate cells, testosterone treatment increases IL-12, and IL- $1 \beta$ production in monocytes, whilst reducing IL-6 $(99,100)$. In DCs it reduces Th2 responses including suppressing IL-4, IL-10, and IL-13 production (129). Conversely, following TLR stimulation, estrogen induces the genes TLR7, MYD88, RIG1, IRF7, IFNB, AJK2, STAT3, NFKB, IFNG, and TNF-many of which have estrogen response elements in their promoters $(62,139)$. Consequently, these genes have higher expression in females after vaccination (139). Estrogens also elicit rapid non-nuclear responses via binding estrogen receptors associated with the inner plasma membrane. This activates NO and cyclic AMP production, the mobilization of intracellular calcium and the stimulation of protein kinase pathways, such as PI3K/AKT and ERK (112).

With respect to changes in lymphocyte populations as children progress into adolescence, as sex hormones begin to exert their effects on cell development, differences in the frequency of different cell populations begin to emerge. Males have been shown to have a higher number of circulating CD8 and NK cells, indicating a higher frequency of cytotoxic cells $(62,133)$. Males develop a more robust innate immune response early in development (140), which may contribute to early infection control and slower disease progression. However, once disease develops, these features may contribute to greater immunopathology and severity of disease in males. Conversely, females develop higher circulating levels of immunoglobulins (Igs) and B cell receptor expression (136); a lower number of $\mathrm{B}$ cells; a higher number of $\mathrm{CD} 4+\mathrm{T}$ cells; and a higher CD4:CD8 ratio $(86,141,142)$. Given the recent support of Fc-mediated antibody protection in latently infected individuals, including enhanced phagolysosomal maturation and antimycobacterial activity of macrophages (143), the decreased antibody production and B cell proliferation in males may contribute to gender differences in $\mathrm{TB}$ prevalence and presentation.

The difference in TB case prevalence between genders begins to appear in mid-adolescence (144). This timing corresponds to the steep rise in production of adrenarchal and gonadarchal hormones, which decline in the fourth or fifth decade of life (Figure 3) (81, 145-147). Levels of leptin, also follow the same pattern (148). These hormonal declines correspond temporally to the fall in TB rates, which occurs earlier and faster in women and corresponds to the transition into menopause, which generally begins in the late 30 s or early 40 s $(62,144)$. The association of a rise and decline in $\mathrm{TB}$ risk with the rise and decline in sex hormones supports a potential role for these hormones in controlling the inflammatory imbalance that leads to TB disease progression.

Sex differences in immune responses have been identified for the "type" of inflammatory response produced, i.e., Th1 vs. Th2; the level of regulation governed by transcriptional and posttranscriptional modifications; and differences in the absolute number of different circulating cell populations (Table 2 and Figure 4). These differences can be due to differential exposure to sex hormones, as well as genetic and epigenetic differences impacting gene expression.

As the outcome of infection depends on the immune pathways activated by the pathogen and the pre-existing environment and propensity of the host to respond to those stimuli $(140,149)$, the sexually distinct activation pathways likely impact infection outcome. It has been hypothesized that even though females elicit more immune-enhancing effects, due to their inherent Th2 skewing, they have a more controlled response to Th1-inducing pathogens (140). Males, although generally immune-suppressive, are Th1-skewed, and thus are likely to elicit an exaggerated response to Th1-inducing pathogens, such a $M$. tuberculosis (140). Conversely, the strong Th2 and humoral response of females is hypothesized to be the underlying cause of higher rates of autoimmune diseases experienced by females $(89,150)$.

This gender difference in inflammatory response may explain the difference in $M t b$ lineages identified in TB patients due to an interaction between the inherent host inflammatory response and inflammatory pathways activated by different $M t b$ lineages (151). A recent large population study in Vietnam tracing $1635 \mathrm{Mtb}$ strains by whole genome sequencing found that young people and females in particular are more susceptible to TB caused by the Beijing 2.2 lineage whilst males and the elderly are more susceptible to Lineage 1 strains (152). 
TABLE 2 | Impact of hormones on components of the immune system implicated in the immune response to Mycobacterium tuberculosis, as reported in humans, animals, and in vitro models.

\begin{tabular}{|c|c|c|c|c|c|c|}
\hline General response & DHEA(S) & Adiponectin & Leptin & Oestradiol & Progesterone & Testosterone \\
\hline Immune phenotype $(87,88)$ & Enhancing & Suppressive & Enhancing & Enhancing & Suppressive & Suppressive \\
\hline T cell polarization $(63,67,68,87,89)$ & Th1 & & Th1 & Th2 & Th2 & Th1 \\
\hline \multicolumn{7}{|l|}{ MACROPHAGE ACTIVITY } \\
\hline TNF expression $\$(64,70-72,90-97)$ & $\uparrow$ & $\downarrow$ & $\boldsymbol{\top}$ & $\begin{array}{l}\boldsymbol{N} \text { at low levels, } \\
\boldsymbol{\nu} \text { at high levels }\end{array}$ & $\downarrow$ & $\uparrow$ \\
\hline IL-12 expression $\$(63,64,90,91,97,98)$ & $\uparrow$ & $\downarrow$ & $\boldsymbol{\top}$ & $\uparrow$ & $\downarrow$ & \\
\hline IL-1 $\beta$, IL-6 expression $(70,71,99-101)$ & & & & $\begin{array}{l}\text { Tat low levels, } \\
\boldsymbol{v} \text { at high levels }\end{array}$ & $\downarrow$ & $\boldsymbol{T}$ \\
\hline IFN $\alpha$ expression (102) & & & & $\uparrow$ & & \\
\hline Foam cell differentiation (103-109) & $\uparrow$ & $\downarrow$ & $\boldsymbol{\sim}$ & $\downarrow$ & $\downarrow$ & $\boldsymbol{A}$ \\
\hline Phagocytic activity $(97,110,111)$ & & & $\boldsymbol{\top}$ & $\uparrow$ & $\downarrow$ & $\downarrow$ \\
\hline Microbial activity (iNOS, NO) (73, 112-115) & & & $\boldsymbol{\sim}$ & $\uparrow$ & $\downarrow$ & $\downarrow$ \\
\hline Autophagy of Mtb-infected macrophages (116) & $\uparrow$ & & & & & \\
\hline Lung granuloma formation ${ }^{\S}(97,114,117)$ & & & $\boldsymbol{T}$ & $\uparrow$ & & $\downarrow$ \\
\hline \multicolumn{7}{|l|}{ DENDRITIC CELL ACTIVITY } \\
\hline MHC expression $(70,90,91,118)$ & $\uparrow$ & $\downarrow$ & & $\uparrow$ & $\downarrow$ & \\
\hline CD1a $^{+}$expression (119) & & $\downarrow$ & & & & \\
\hline \multicolumn{7}{|l|}{ NEUTROPHIL ACTIVITY } \\
\hline Numbers $(62,120)$ & & & & $\uparrow$ & & $\boldsymbol{\sim}$ \\
\hline Degranulation (62) & & & & $\uparrow$ & & \\
\hline Apoptosis (121) & & & & $\downarrow$ & $\downarrow$ & \\
\hline Phagocytosis (122-124) & & & & $\uparrow$ & & $\downarrow$ \\
\hline \multicolumn{7}{|l|}{ LYMPHOCYTE ACTIVITY } \\
\hline $\begin{array}{l}\text { IFN } \gamma \text { expression } \\
(63,64,90,91,97,117,125,126)\end{array}$ & $\uparrow$ & $\downarrow$ & $\boldsymbol{T}$ & $\uparrow$ & $\downarrow$ & $\downarrow$ \\
\hline Th1 differentiation $(87,91,127,128)$ & $\uparrow$ & & $\boldsymbol{\uparrow}$ & $\begin{array}{l}\boldsymbol{N} \text { at low levels, } \\
\Downarrow \text { at high levels }\end{array}$ & $\downarrow$ & $\boldsymbol{T}$ \\
\hline Th2 $(63,67,68,87,89,129)$ & & & & $\uparrow$ & $\uparrow$ & $\downarrow$ \\
\hline Th17 $(75,87,130)$ & & & & $\downarrow$ & $\downarrow$ & $\downarrow$ \\
\hline FOXP3, Treg $(49,131,132)$ & & & & $\uparrow$ & $\uparrow$ & $\boldsymbol{T}$ \\
\hline $\begin{array}{l}\text { Cytotoxicity of NK and CD8 } \\
(62,74,98,133,134)\end{array}$ & & & & $\downarrow$ & $\downarrow$ & $\boldsymbol{T}$ \\
\hline $\begin{array}{l}\text { IFN } \gamma \text { expression from NK and CD8 } \\
(124,126,135)\end{array}$ & & & & $\uparrow$ & $\downarrow$ & $\downarrow$ \\
\hline $\begin{array}{l}\text { B cell proliferation, Antibody production } \\
(87,89,134,136,137)\end{array}$ & & & & $\uparrow$ & $\downarrow$ & $\downarrow$ \\
\hline
\end{tabular}

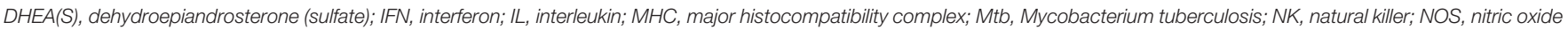

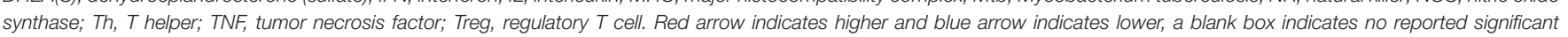
difference.

${ }^{\S}$ Also expressed by or involves dendritic cells and Th1 cells.

\#High levels of estrogen occur during the follicular phase of the menstrual cycle and during pregnancy.

\section{Genetic and Epigenetic Causes of Differential Sexual Responses to Infection}

Differential expression of genes on the $\mathrm{X}$ and $\mathrm{Y}$ chromosomes defines sexual development. Male development is mediated by the SRY gene on the Y chromosome, whilst females regulate $\mathrm{X}$ chromosome expression via $\mathrm{X}$-linked gene inactivation. The differential level of $\mathrm{X}$ inactivation that occurs between males and females can impact the level of expression of X-linked genes between sexes [reviewed in Markle and Fish (60)]. The X chromosome also contains $\sim 10 \%$ of all 800 microRNA produced by humans, whilst the $\mathrm{Y}$ chromosome accounts for only $2 \%$ (153). Incomplete $\mathrm{X}$-inactivation in females therefore increases the expression of regulatory miRNA, the expression of which can also be under hormone control, further increasing gene regulation differences between sexes. Toll-like receptor 7 (TLR7) which is activated by viral cytosolic nucleic acids, has higher expression in females than males (102). Subsequently, plasmacytoid dendritic cells $(\mathrm{pDC})$ of females make double the amount of IFN $\alpha$ to 


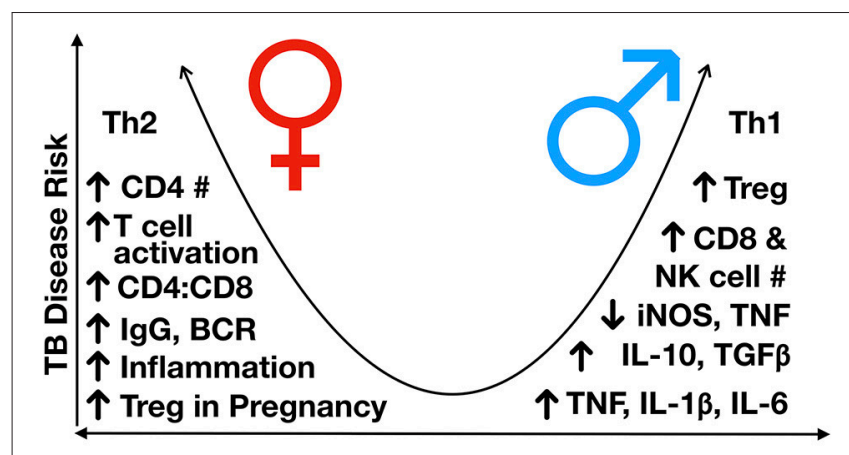

Immune Response

FIGURE 4 | Immunological differences observed between males and females, post-puberty. TB disease risk increases as the immune response more heavily favors either Th2 or Th1 skewing, with a more balanced Th1/Th2 response having the lowest risk of disease progression. In general, males are Th1 skews and females Th2 skewed, although females have a higher inflammatory response to an exogenous stimulus, partly mediated by variable $\mathrm{X}$-inactivation and the presence of estrogen response elements in many immune response genes, leading to higher responses once activated. BCR, B cell receptor; Ig, immunoglobulin; IL, interleukin; NK, natural killer; iNOS, inducible nitric oxide synthase; Th, T helper; TGFB, transforming growth factor-beta; TNF, tumor necrosis factor; \#, number.

TLR7 ligands, such as HIV (154). Type 1 interferons, IFN $\alpha$ and IFN $\beta$, have recently been shown to have detrimental effects on $M$. tuberculosis control depending on their context of activation $(155,156)$; this finding suggests this difference in females may contribute to exacerbating an inflammatory imbalance, skewed to $M$. tuberculosis survival and proliferation. Conversely, in response to TLR8 and TLR9 agonists, male androgens suppress macrophage phagocytic activity, and correlate to higher IL-10 secretion (157). In addition, males have higher pro-inflammatory production following LPS stimulation of TLR4, including higher TNF production from neutrophils (158). Thus, viral and bacterial responses in males and females may also differ according to TLR expression and activation in each sex. Of particular relevance to $\mathrm{TB}$ pathology, compared to monocytes and $\mathrm{T}$ cells, neutrophils have greater differences in global methylation and gene expression profiles between males and females (159). Twenty-one genes expressed from neutrophils were identified to be differentially expressed between sexes. Meanwhile, one of the top two differentially expressed genes between male and female neutrophils, SEPT4, is often found in the neutrophil-driven whole blood signatures of TB (160-162).

\section{Sex Hormone Impact on Response to $M$. tuberculosis}

As shown in Table 2, hormones may impact adolescent TB through multiple plausible mechanisms and potentially in a multifactorial manner. Increased $\operatorname{DHEA}(S)$ and leptin levels may promote foam cell differentiation (103-106), leading to disease progression and lung cavitation. DHEA(S), estradiol, and leptin may contribute to disease severity by promoting aggressive Th1 responses $(63,90,91,118,127,128)$. A study comparing TST response after Bacillus Calmette-Guérin (BCG) vaccination gives clinical support to the association between $\operatorname{DHEA}(\mathrm{S})$ and Th1 responses; in this study, pubertal subjects had higher DHEAS levels and larger TST reactions than prepubertal subjects (163). Likewise, the link between gonadarche and disease severity is strengthened by a guinea pig model that demonstrated associations between increased exposure to oestradiol and testosterone and greater mortality and more extensive, caseous lung lesions (164). Suppression of TNF by $\operatorname{DHEA}(\mathrm{S})$ may also contribute to disease progression (92-96).

The greater resistance of female mice to mycobacterium species has been demonstrated in a number of studies (113, $114,165,166)$. In a C57BL/6 mouse model of TB, male mice have accelerated disease and increased mortality compared to females. The male mice had increased lung bacterial loads, increased iNOS, IFN $\gamma$, IL- $1 \alpha / \beta$, and IL- 6 production early and late in infection, and higher levels of various inflammatory chemokines, all of which correlated with increased bacterial burden (114). Castration of male BALB/c mice reduced mortality and increased levels of inflammation to those seen in female mice (113). However, converse to what was seen in $\mathrm{C} 57 \mathrm{BL} / 6$ mice, during early infection, female and castrated $\mathrm{BALB} / \mathrm{c}$ expressed higher lungs levels of TNF, IFNG, IL12, iNOS, and IL17 than non-castrated males. Moreover, castration 60 days after infection increased the survival of male mice, decreasing bacterial load and increasing TNF, IFNG, and IL12. Interestingly, whilst female castration resulted in declines in bacterial numbers early during infection, they rose at day 60 compared to noncastrated females. Testosterone treatment of female mice also increases susceptibility to M. marinum (165), whilst oestradiol treatment of ovariectomised mice increases mycobacterial killing, synergistically with IFN $\gamma$ (167). Testosterone treatment of rats increased recruitment of inefficient neutrophils following LPS treatment, with impaired bacterial activity decreased MPO activity and increased IL-10 and TGF $\beta$ expression (168). Together, these studies suggest that high levels of testosterone can contribute to disease progression in males, whilst estrogen elicits a more protective response. However, the difference in genetic backgrounds of the animals infected also creates different inflammatory processes correlated to disease. Thus, the effect of hormones will be governed by the overall inflammatory state of the individual, which may be further governed genetically, epigenetically or environmentally by other co-morbidities, including co-infections.

\section{BEYOND AGE- AND SEX-RELATED IMMUNOLOGICAL CHANGES IN CHILDREN AND ADOLESCENTS}

Although age- and sex-related changes in the immune response to $M$. tuberculosis are a critical factor in the relative reduction in TB disease prevalence in primary school children and increase in adolescence, it is important to consider other contributing factors (Figure 3). The degree of TB exposure is one alternative explanation for and/or contributing factor to different risks of disease progression. A study from Canada found that among recently infected individuals, those who developed TB disease 
had exposure to a higher number of infectious TB cases than those who did not (169). At the same time, a recent animal study suggested that repetitive aerosol exposure with $M$. tuberculosis drives greater lung tissue destruction, including cavitation, than a single exposure (170). This explanation fits with the increased socialization in adolescence that is assumed to occur in many societies, and may contribute to increased risk of TB progression (171). This generalization about adolescent social mixing is supported by data from various settings, including eight European countries, rural Andean communities in Peru, a South African township, and a city in Siberia, Russia. These cross-sectional surveys all found that on a daily basis, adolescents come into contact with 1.5- to 3-times as many individuals as young children do (172-176). However, the hypothesis that a higher number of $\mathrm{TB}$ exposures increases the probability of TB disease progression does not account for the higher risks observed in young children vis-à-vis primary school children, or adolescent girls vis-à-vis adolescent boys. Young children come into contact with fewer individuals on a daily basis than primary school children (172-176), and to our knowledge, there are no data to suggest that adolescent girls have more frequent exposure to infectious TB cases compared to adolescent boys. The social mixing studies showed no difference in mean number of contacts for females vs. males, but these data were not age-disaggregated $(172,175)$.

On the other hand, if one of the drivers of risk of disease progression is the intensity of exposure (i.e., the size of the bacillary load), then the increased risk during early childhood makes more sense. Data from various settings support the idea that young children, particularly those $<2$ years of age, spend more time with household contacts than primary school children and adolescents $(173,175,176)$; thus, they are exposed to a larger inoculum of $M$. tuberculosis from caregivers with TB disease. For this reason, young children are more likely than older children and adolescents to become TB-infected from a household exposure $(177,178)$. However, when comparing primary school children and adolescents, social mixing studies did not find significant differences in the amount of time spent with individual contacts (173-175).

Initiation of substance use and sexual activity also may contribute to the increase in TB disease progression and mortality in adolescents. Recreational drugs, alcohol, and smoking all are associated with increased risk of TB disease (179-182). Sexual activity may lead to pregnancy, which can predispose a woman to TB disease progression due to a wide range of immunosuppressive effects $(183,184)$. Moreover, sexual activity increases the risk of acquiring transmissible infections, including HIV.

Among co-infections that may contribute to the age- and sexrelated changes seen in TB risk, HIV is likely the most significant. As individuals enter adolescence and commence sexual activity, girls are more likely than boys to acquire HIV (185). Globally, adolescent females have higher HIV seroprevalence than adolescent males (186). Because HIV dramatically increases the risk of TB disease progression following infection $(187,188)$, this difference in seroprevalence may contribute to the higher TB disease risk in adolescent girls. It is possible that HIV prevalence is lower in the primary school years compared to both early childhood and adolescence, since untreated vertically transmitted HIV leads to death in $\sim 60 \%$ of children before age 2 years (189) and primary school children have minimal risk of horizontal transmission. However, this possibility is difficult to confirm because, to our knowledge, global childhood HIV prevalence has not been disaggregated into 5-year age bands (190). The data on age-based differences in risk of TB disease progression were collected prior to the HIV epidemic and exist in regions with little HIV; thus, HIV epidemiology cannot be the sole reason for ageand sex-based discrepancies in TB risk.

Other pathogens also may alter an individual's susceptibility to $\mathrm{TB}$ disease. Cytomegalovirus (CMV) has been implicated in TB disease pathogenesis (191); it exerts profound immunodysfunction on infants, and has been associated with increased TB risk in this age group $(192,193)$. Moreover, increases in CMV seroprevalence are highest during infancy and adolescence, and the acceleration of CMV seroprevalence is steeper in adolescent girls than boys (191).

TB epidemics demonstrate a seasonal pattern and follow influenza outbreaks (194-196). A study conducted in a Danish TB sanatorium in the mid-twentieth century found that a strong association between influenza and clinical exacerbation of TB (197). Other studies have found associations between influenza and excess TB mortality (198-200). It is possible that influenzaand perhaps other viruses affecting the lower respiratory tractmay predispose to TB disease progression and mortality by disrupting mucosal integrity and altering host immunology. This link could partially explain the increased TB risks experienced by young children, who are vulnerable to severe lower respiratory disease due to influenza and other respiratory viruses. As children reach primary school age, they become less vulnerable to lung disease from common respiratory viruses (201). With the notable exception of the 1918-1919 influenza pandemic, adolescents do not experience increased morbidity and mortality from respiratory viruses (200). Therefore, this hypothesis does not explain the rise in TB risk during adolescence.

Finally, helminths and malaria infections are both common in young children in high TB-burden settings and cause immune dysregulation that could impact TB risk (202-205). However, the incidence of these infections do not rise again during adolescence, so they do not explain the adolescents' elevated TB risk. It is therefore possible that different etiologies contribute to the elevated risk in young children and adolescents. Further research is needed to disentangle the contribution of exposure intensity and frequency, substance use, and co-infections to the $\mathrm{U}$-shaped pattern of TB risk during childhood and adolescence.

\section{IMPLICATIONS}

The Wonder Years offer a unique insight into the immunological protection against TB disease progression. We have made the case that if infected during this period the host response is effective in containing $M$. tuberculosis within granuloma in contrast to younger children, who more commonly progress to disseminated disease. In addition, primary school children 
are also less likely to mount a tissue damaging, inflammatory response to $M$. tuberculosis. They frequently experience localized bacillary replication within the lung and are less likely than postpubescent adolescents and young adults to develop cavitation. Thus, comparing age-related immunological changes that occur before, during, and after puberty may reveal immunological pathways that could be targeted to promote balanced protective immunity.

Development of an effective TB vaccine has been hampered by insufficient understanding of protective immunity. Given that the presentation of disease and underlying immunological responses change during different risk periods, the approach to inducing an optimal vaccine response in young children may differ to the approach needed in adolescents and adults. Strategies in infants or young children could be aimed at either preventing the establishment of infection by priming the innate immune system or promoting cell-mediated immunity that provides superior protection from dissemination than BCG. Strategies for adolescents could aim to: clear mycobacteria before the stage of increased progression risk; enhance containment within the granuloma; or attenuate the excessive inflammatory response should containment break down. It may be appropriate to revaccinate children prior to adolescence (potentially with a vaccine of different mechanism) or provide host-directed therapies following exposure. Furthermore, the difference in host response of adolescent boys and girls may need to be modulated by vaccines and immunotherapies in different ways. This is supported by the first successful outcome of the new M72 TB vaccine, which demonstrated $57 \%$ efficacy in the population, but $75 \%$ efficacy in males and $84 \%$ efficacy in those $\leq 25$ years, although this secondary analysis is confounded by the enrolled population being skewed toward young males (206). Future vaccine studies must be designed with sufficient power to rigorously test the effect of age and gender on trial outcomes.

In addition, approaches to diagnostics may have to factor in age and sex. Recently, there has been great interest in whole blood transcriptional signatures as potential diagnostics and prognostics for $\mathrm{TB}$ infection and disease. These biomarkers identify a characteristic host response to a particular disease process; however, in TB, pathogenesis of disease may vary by age and, to a lesser extent, by sex. As a result, a transcriptional signature that performs well in diagnosing adult-type pulmonary disease may not capture disease in children, and vice versa.

Ultimately, more research is required to better understand how immunological responses to $M$. tuberculosis change with age and sex. Animal studies, including the use of juvenile animals, could assist in delineating the impact of age and sex on host response to $M$. tuberculosis, as well as the changing disease phenotypes that result. It would also be possible to evaluate different vaccination strategies and host-directed therapies to

\section{REFERENCES}

1. Houben RM, Dodd PJ. The global burden of latent tuberculosis infection: a re-estimation using mathematical modelling. PLoS Med. (2016) 13:e1002152. doi: 10.1371/journal.pmed.1002152 prevent infection and/or disease progression in these animal models. Longitudinal cohorts of young children either prior to TB exposure, or following known exposure, could contribute vital information. In these cohorts, blood samples could be taken at regular intervals to document cell phenotypes and functions and to understand immunological risk factors for disseminated disease. For adolescents, longitudinal cohorts would also be informative, with children identified prior to puberty and with an evaluation of how host immunological responses change with age, puberty, and with sex. Specific attention to methylation profiles of boys and girls at different ages may identify the changes induced by puberty which could impact disease risk and protective immunity. Impact of co-infections in both young children and adolescents would be important to consider. Although longitudinal cohorts are expensive to conduct, it is often strategic and efficient to undertake such studies within the framework of therapeutic clinical trials or vaccine trials.

\section{CONCLUSIONS}

Primary school children teach us that there is still much about TB that we do not understand. They sit within the flexion point where TB pathology and risk changes; the immunological changes that occur during early childhood and puberty are likely to impact the response to infection and risk of disease. The difference in TB risk that emerges after puberty also indicates that diagnostics and strategies for prevention and treatment may need to be targeted according age and sex.

\section{AUTHOR CONTRIBUTIONS}

All authors listed have made a substantial, direct and intellectual contribution to the work, and approved it for publication.

\section{FUNDING}

JS is supported by a Clinician Scientist Fellowship jointly funded by the UK Medical Research Council (MRC) and the UK Department for International Development (DFID) under the MRC/DFID Concordat agreement (MR/R007942/1). SC is supported by the U.S. National Institutes of Health, Fogarty International Center (K01TW010829). HE is supported by National Research Foundation of South Africa and Oxford University Clinical Academic School. AC is supported by the Walter and Eliza Hall Institute of Medical Research, the Medical Research Council of South Africa (SHIP-02-2013), the National Institute of Health TB Research Unit (U19AI111276), and the South African National Research Foundation (UID109040). HE is also funded by a James Maxwell Grant Prophit Fellowship from the Royal College of Physicians UK.
2. Dodd PJ, Sismanidis C, Seddon JA. Global burden of drug-resistant tuberculosis in children: a mathematical modelling study. Lancet Infect Dis. (2016) 16:1193-201. doi: 10.1016/S1473-3099(16)30132-3

3. World Health Organization. Global Tuberculosis Report. Geneva: World Health Organization (2017). Available online at: http://apps.who.int/iris/ 
bitstream/10665/259366/1/9789241565516-eng.pdf?ua=1 (Accessed June 11, 2018).

4. Marais BJ, Gie RP, Schaaf HS, Hesseling AC, Obihara CC, Starke JJ, et al. The natural history of childhood intra-thoracic tuberculosis: a critical review of literature from the pre-chemotherapy era. Int J Tuberc Lung Dis. (2004) 8:392-402.

5. Dodd PJ, Yuen CM, Sismanidis C, Seddon JA, Jenkins HE. The global burden of tuberculosis mortality in children: a mathematical modelling study Lancet Global Health (2017) 5:e898-906. doi: 10.1016/S2214-109X(17) 30289-9

6. Weber HC, Beyers N, Gie RP, Schaaf HS, Fish T, Donald PR. The clinical and radiological features of tuberculosis in adolescents. Ann. Trop. Paediatr.(2000) 20:5-10. doi: 10.1080/027249300 91995

7. de Pontual L, Balu L, Ovetchkine P, Maury-Tisseron B, Lachassinne E, Cruaud P, et al. Tuberculosis in adolescents: a French retrospective study of 52 cases. Pediatr Infect Dis J. (2006) 25:930-2. doi: 10.1097/01.inf.0000237919.53123.f4

8. Cruz AT, Hwang KM, Birnbaum GD, Starke JR. Adolescents with tuberculosis: a review of 145 cases. Pediatr Infect Dis J. (2013) 32:937-41. doi: 10.1097/INF.0b013e3182933214

9. Del Castillo-Barrientos H, Centeno-Luque G, Untiveros-Tello A, Simms B, Lecca L, Nelson AK, et al. Clinical presentation of children with pulmonary tuberculosis: 25 years of experience in Lima, Peru. Int J Tuberc Lung Dis. (2014) 18:1066-73. doi: 10.5588/ijtld.13.0458

10. World Health Organization. Health for the World's Adolescents. Geneva: World Health Organization (2014).

11. Clayton JA, Tannenbaum C. Reporting sex, gender, or both in clinical research? JAMA (2016) 316:1863-4 doi: 10.1001/jama.2016. 16405

12. Esmail H, Barry CE III, Young DB, Wilkinson RJ. The ongoing challenge of latent tuberculosis. Philos Trans R Soc Lond. (2014) 369:20130437 doi: $10.1098 /$ rstb.2013.0437

13. Perez-Velez CM, Marais BJ. Tuberculosis in children. N Engl J Med. (2012) 367:348-61. doi: 10.1056/NEJMra1008049

14. Chiang SS, Starke JR. Mycobacterium tuberculosis. In: Long SS, Prober CG, Fischer M, editors. Principles and Practices of Pediatric Infectious Diseases. 5th ed. Elsevier (2017). p. 795-811.

15. Marais BJ, Gie RP, Schaaf HS, Hesseling AC, Enarson DA, Beyers N. The spectrum of disease in children treated for tuberculosis in a highly endemic area. Int J Tuberc Lung Dis. (2006) 10:732-8.

16. van Toorn R, Solomons R. Update on the diagnosis and management of tuberculous meningitis in children. Semin. Pediatric Neurol. (2014) 21:12-8. doi: 10.1016/j.spen.2014.01.006

17. Lincoln EM. Tuberculous meningitis in children; with special reference to serous meningitis; tuberculous meningitis. Am Rev Tuberc. (1947) 56:75-94.

18. Comstock GW, Livesay VT, Woolpert SF. The prognosis of a positive tuberculin reaction in childhood and adolescence. Am J Epidemiol. (1974) 99:131-8. doi: 10.1093/oxfordjournals.aje.a121593

19. Donald PR. The North American contribution to our knowledge of childhood tuberculosis and its epidemiology. Int J Tuberc Lung Dis. (2014) 18:890-8. doi: 10.5588/ijtld.13.0915

20. Marais BJ, Gie RP, Hesseling AH, Beyers N. Adult-type pulmonary tuberculosis in children 10-14 years of age. Pediatr Infect Dis J. (2005) 24:743-4. doi: 10.1097/01.inf.0000173305.04212.09

21. Van Zwanenberg D. The influence of the number of bacilli on the development of tuberculous disease in children. Am Rev Respir Dis. (1960) 82:31-44.

22. Myers JA, Bearman JE, Dixon HG. The natural history of the tuberculosis in the human body. V. Prognosis among tuberculin-reactor children from birth to five years of age. Am Rev Respir Dis. (1963) 87:354-69. doi: 10.1164/arrd.1963.87.3P1.354

23. Myers JA, Bearman JE, Dixon HG. Natural history of tuberculosis in the human body. Vi. Prognosis among tuberculin reactor children of six to twelve years. Am Rev Respir Dis. (1964) 90:359-69.

24. Myers JA, Bearman JE, Dixon HG. Natural history of tuberculosis in the human body. 8. Prognosis among tuberculin reactor girls and boys of thirteen to seventeen years. Am Rev Respir Dis. (1965) 91:896-908.
25. Pope AS, Sartwell PE, Zacks D. Development of tuberculosis in infected children. Am J Public Health Nations Health (1939) 29:1318-25. doi: 10.2105/AJPH.29.12.1318

26. Davies PDB. The Natural History of Tuberculosis in Children: A Study of Child Contacts in the Brompton Hospital Child Contact Clinic from 1930 to 1952. London: E. \& S. Livingstone Ltd (1961).

27. Gedde-Dahl T. Tuberculous infection in the light of tuberculin matriculation. Am J Hyg. (1952) 56:139-214.

28. Miller FJW, Seal RME, Taylor MD. Tuberculosis in Children. London: J and A Churchill Ltd (1963).

29. Bentley FJ, Grzybowski S, Benjamin B. Tuberculosis in Childhood and Adolescence: with Special Reference to the Pulmonary Forms of the Disease. London: The National Association for the Prevention of Tuberculosis (1954).

30. Opie EL, McPhedran FM, Putnam P. The fate of persons in contact with tuberculosis: the exogenous infection of children and adults. Am J Hyg. (1935) 22:644-82.

31. Brailey M. Mortality in the Children of Tuberculous Households. Am J Public Health Nations Health (1940) 30:816-23. doi: 10.2105/AJPH.30.7.816

32. Frost WH. The age selection of mortality from tuberculosis in successive decades. 1939. Am J Epidemiol. (1995) 141:4-9; discussion 3 doi: 10.1093/oxfordjournals.aje.a117343

33. Frost WH. Risk of persons in familial contact with pulmonary tuberculosis. Am J Public Health Nations Health (1933) 23:426-32. doi: 10.2105/AJPH.23.5.426

34. Wallgren A. Pulmonary tuberculosis: relation of childhood infection to disease in adults. Lancet (1938) 1:5973-76. doi: 10.1016/S0140-6736(00)86179-6

35. Lincoln EM, Sewell EM. Tuberculosis in Children. New York, NY: McGrawHill Book Company, Inc (1963).

36. Tuberculosis Surveillance Research Unit of the International Union against Tuberculosis. Progress Report Part I. Hague (1967).

37. Sutherland I. The Ten-Year Incidence of Clinical Tuberculosis Following 'Conversion' in 2,550 Individuals Aged 14 to 19 at the Time of Conversion. Tuberculosis Surveillance Research Unit Progress Report (1968).

38. Wood R, Liang H, Wu H, Middelkoop K, Oni T, Rangaka MX, et al. Changing prevalence of tuberculosis infection with increasing age in highburden townships in South Africa. Int J Tuberc Lung Dis. (2010) 14:406-12.

39. Jenkins HE, Yuen CM, Rodriguez CA, Nathavitharana RR, McLaughlin MM, Donald P, et al. Mortality in children diagnosed with tuberculosis: a systematic review and meta-analysis. Lancet Infect Dis (2017) 17:285-95. doi: 10.1016/S1473-3099(16)30474-1

40. Medical Research Council. BCG and vole bacillus vaccines in the prevention of tuberculosis in adolescence and early adult life. Bull World Health Organ (1972) 46:371-85.

41. Lincoln EM. Course and prognosis of tuberculosis in children. Am J Med. (1950) 9:623-32. doi: 10.1016/0002-9343(50)90212-9

42. Comstock GW, Ferebee SH, Hammes LM. A controlled trial of communitywide isoniazid prophylaxis in Alaska. Am Rev Respir Dis. (1967) 95:935-43.

43. Grzybowski S, Allen EA. The challenge of tuberculosis in decline. a study based on the epidemiology of tuberculosis in Ontario, Canada. Am Rev Respir Dis. (1964) 90:707-20.

44. Holmes CB, Hausler H, Nunn P. A review of sex differences in the epidemiology of tuberculosis. Int J Tuberc Lung Dis. (1998) 2:96-104.

45. Silva Miranda M, Breiman A, Allain S, Deknuydt F, Altare F. The tuberculous granuloma: an unsuccessful host defence mechanism providing a safety shelter for the bacteria? Clin Dev Immunol. (2012) 2012:139127 doi: 10.1155/2012/139127

46. Peyron P, Vaubourgeix J, Poquet Y, Levillain F, Botanch C, Bardou F, et al. Foamy macrophages from tuberculous patients' granulomas constitute a nutrient-rich reservoir for M. tuberculosis persistence. PLoS Pathog. (2008) 4:e1000204. doi: 10.1371/journal.ppat.1000204

47. Lay G, Poquet Y, Salek-Peyron P, Puissegur MP, Botanch C, Bon $\mathrm{H}$, et al. Langhans giant cells from $M$. tuberculosis-induced human granulomas cannot mediate mycobacterial uptake. J Pathol. (2007) 211:7685 doi: 10.1002/path.2092

48. Newton SM, Brent AJ, Anderson S, Whittaker E, Kampmann B. Paediatric tuberculosis. Lancet Infect Dis. (2008) 8:498-510. doi: 10.1016/S1473-3099(08)70182-8 
49. Simon AK, Hollander GA, McMichael A. Evolution of the immune system in humans from infancy to old age. Proc Biol Sci. (2015) 282:20143085 doi: $10.1098 / \mathrm{rspb} .2014 .3085$

50. Trunz BB, Fine P, Dye C. Effect of BCG vaccination on childhood tuberculous meningitis and miliary tuberculosis worldwide: a metaanalysis and assessment of cost-effectiveness. Lancet (2006) 367:1173-80. doi: 10.1016/S0140-6736(06)68507-3

51. Dockrell HM, Smith SG. What Have We Learnt about BCG Vaccination in the Last 20 Years? Front. Immunol. (2017) 8:1134. doi: 10.3389/fimmu.2017.01134

52. Martineau AR, Nhamoyebonde S, Oni T, Rangaka MX, Marais S, Bangani $\mathrm{N}$, et al. Reciprocal seasonal variation in vitamin D status and tuberculosis notifications in Cape Town, South Africa. Proc Natl Acad Sci USA. (2011) 108:19013-7. doi: 10.1073/pnas.1111825108

53. Walaza S, Tempia S, Dawood H, Variava E, Moyes J, Cohen AL, et al. Influenza virus infection is associated with increased risk of death amongst patients hospitalized with confirmed pulmonary tuberculosis in South Africa, 2010-2011. BMC Infect Dis. (2015) 15:26 doi: 10.1186/s12879-015-0746-x

54. Hunter RL. Pathology of post primary tuberculosis of the lung: an illustrated critical review. Tuberculosis (2011) 91:497-509. doi: 10.1016/j.tube.2011.03.007

55. Hunter RL. Tuberculosis as a three-act play: a new paradigm for the pathogenesis of pulmonary tuberculosis. Tuberculosis (2016) 97:8-17. doi: 10.1016/j.tube.2015.11.010

56. Mahamed D, Boulle M, Ganga Y, Mc Arthur C, Skroch S, Oom L, et al. Intracellular growth of Mycobacterium tuberculosis after macrophage cell death leads to serial killing of host cells. Elife (2017) 6:e22028. doi: 10.7554/eLife. 22028

57. Ridley MJ, Ridley DS. Histochemical demonstration of mycobacterial antigen, specific antibody and complement in the lesions of tuberculosis. Histochem J. (1986) 18:551-6. doi: 10.1007/BF01675196

58. Lowe DM, Redford PS, Wilkinson RJ, O'Garra A, Martineau AR. Neutrophils in tuberculosis: friend or foe? Trends Immunol. (2012) 33:14-25. doi: 10.1016/j.it.2011.10.003

59. Elkington PT, D'Armiento JM, Friedland JS. Tuberculosis immunopathology: the neglected role of extracellular matrix destruction. Sci Transl Med. (2011) 3:71ps6. doi: 10.1126/scitranslmed.3001847

60. Markle JG, Fish EN. SeXX matters in immunity. Trends Immunol. (2014) 35:97-104. doi: 10.1016/j.it.2013.10.006

61. vom Steeg LG, Klein SL. SeXX matters in infectious disease pathogenesis. PLoS Pathog. (2016) 12:e1005374. doi: 10.1371/journal.ppat.1005374

62. Klein SL, Flanagan KL. Sex differences in immune responses. Nat Rev Immunol. (2016) 16:626-38. doi: 10.1038/nri.2016.90

63. Fish EN. The X-files in immunity: sex-based differences predispose immune responses. Nat Rev Immunol. (2008) 8:737-44. doi: 10.1038/nri2394

64. Kovats S. Estrogen receptors regulate innate immune cells and signaling pathways. Cell Immunol. (2015) 294:63-9. doi: 10.1016/j.cellimm.2015.01.018

65. Fu M, Liu M, Sauve AA, Jiao X, Zhang X, Wu X, et al. Hormonal control of androgen receptor function through SIRT1. Mol Cell Biol. (2006) 26:812235. doi: 10.1128/MCB.00289-06

66. Levy O. Innate immunity of the newborn: basic mechanisms and clinical correlates. Nat Rev Immunol. (2007) 7:379-90. doi: 10.1038/ nri2075

67. Robinson DP, Klein SL. Pregnancy and pregnancy-associated hormones alter immune responses and disease pathogenesis. Horm Behav. (2012) 62:263-71. doi: 10.1016/j.yhbeh.2012.02.023

68. Piccinni MP, Giudizi MG, Biagiotti R, Beloni L, Giannarini L, Sampognaro S, et al. Progesterone favors the development of human $\mathrm{T}$ helper cells producing Th2-type cytokines and promotes both IL-4 production and membrane CD30 expression in established Th1 cell clones. J Immunol. (1995) 155:12833.

69. Teilmann SC, Clement CA, Thorup J, Byskov AG, Christensen ST. Expression and localization of the progesterone receptor in mouse and human reproductive organs. J Endocrinol. (2006) 191:525-35. doi: $10.1677 /$ joe. 1.06565
70. Butts CL, Shukair SA, Duncan KM, Bowers E, Horn C, Belyavskaya E, et al. Progesterone inhibits mature rat dendritic cells in a receptor-mediated fashion. Int Immunol. (2007) 19:287-96. doi: 10.1093/intimm/dxl145

71. Jones LA, Kreem S, Shweash M, Paul A, Alexander J, Roberts CW. Differential modulation of TLR3- and TLR4-mediated dendritic cell maturation and function by progesterone. J Immunol. (2010) 185:4525-34. doi: 10.4049/jimmunol.0901155

72. Butts CL, Bowers E, Horn JC, Shukair SA, Belyavskaya E, Tonelli L, et al. Inhibitory effects of progesterone differ in dendritic cells from female and male rodents. Gend Med. (2008) 5:434-47. doi: 10.1016/j.genm.2008. 11.001

73. Menzies FM, Henriquez FL, Alexander J, Roberts CW. Selective inhibition and augmentation of alternative macrophage activation by progesterone. Immunology (2011) 134:281-91. doi: 10.1111/j.1365-2567.2011. 03488.x

74. Arruvito L, Giulianelli S, Flores AC, Paladino N, Barboza M, Lanari $\mathrm{C}$, et al. NK cells expressing a progesterone receptor are susceptible to progesterone-induced apoptosis. J Immunol. (2008) 180:5746-53. doi: 10.4049/jimmunol.180.8.5746

75. Lee JH, Ulrich B, Cho J, Park J, Kim CH. Progesterone promotes differentiation of human cord blood fetal $\mathrm{T}$ cells into $\mathrm{T}$ regulatory cells but suppresses their differentiation into Th17 cells. J Immunol. (2011) 187:177887. doi: 10.4049/jimmunol.1003919

76. Kollmann TR, Levy O, Montgomery RR, Goriely S. Innate immune function by Toll-like receptors: distinct responses in newborns and the elderly. Immunity (2012) 37:771-83. doi: 10.1016/j.immuni.2012. 10.014

77. Guilmot A, Hermann E, Braud VM, Carlier Y, Truyens C. Natural killer cell responses to infections in early life. J Innate Immun. (2011) 3:280-8. doi: 10.1159/000323934

78. Manser AR, Uhrberg M. Age-related changes in natural killer cell repertoires: impact on NK cell function and immune surveillance. Cancer Immunol Immunother. (2016) 65:417-26. doi: 10.1007/s00262-015-1750-0

79. Georgountzou A, Papadopoulos NG. Postnatal innate immune development: from birth to adulthood. Front Immunol. (2017) 8:957. doi: 10.3389/fimmu.2017.00957

80. Kollmann TR, Crabtree J, Rein-Weston A, Blimkie D, Thommai F, Wang $\mathrm{XY}$, et al. Neonatal innate TLR-mediated responses are distinct from those of adults. J Immunol. (2009) 183:7150-60. doi: 10.4049/jimmunol. 0901481

81. Auchus RJ, Rainey WE. Adrenarche - physiology, biochemistry and human disease. Clin Endocrinol. (2004) 60:288-96. doi: 10.1046/j.1365-2265.2003.01858.x

82. Kiess W, Reich A, Meyer K, Glasow A, Deutscher J, Klammt J, et al. A role for leptin in sexual maturation and puberty? Horm Res. (1999) 51(Suppl. 3):55-63.

83. Valiathan R, Ashman M, Asthana D. Effects of ageing on the immune system: infants to elderly. Scand J Immunol. (2016) 83:255-66. doi: 10.1111/sji. 12413

84. Hemingway C, Berk M, Anderson ST, Wright VJ, Hamilton S, Eleftherohorinou $\mathrm{H}$, et al. Childhood tuberculosis is associated with decreased abundance of $\mathrm{T}$ cell gene transcripts and impaired $\mathrm{T}$ cell function. PLoS ONE (2017) 12:e0185973. doi: 10.1371/journal.pone. 0185973

85. Dallenga T, Schaible UE. Neutrophils in tuberculosis-first line of defence or booster of disease and targets for host-directed therapy? Pathog Dis. (2016) 74:ftw012. doi: 10.1093/femspd/ftw012

86. Bartlett JA, Schleifer SJ, Demetrikopoulos MK, Delaney BR, Shiflett SC, Keller SE. Immune function in healthy adolescents. Clin Diagn Lab Immunol. (1998) 5:105-13.

87. Foo YZ, Nakagawa S, Rhodes G, Simmons LW. The effects of sex hormones on immune function: a meta-analysis. Biol Rev Camb Philos Soc. (2017) 92:551-71. doi: 10.1111/brv.12243

88. Giron-Gonzalez JA, Moral FJ, Elvira J, Garcia-Gil D, Guerrero F, Gavilan I, et al. Consistent production of a higher TH1:TH2 cytokine ratio by stimulated T cells in men compared with women. Eur J Endocrinol. (2000) 143:31-6. doi: 10.1530/eje.0.1430031 
89. Whitacre CC, Reingold SC, O'Looney PA. A gender gap in autoimmunity. Science (1999) 283:1277-8. doi: 10.1126/science.283.5406.1277

90. Angerami M, Suarez G, Pascutti MF, Salomon H, Bottasso O, Quiroga MF. Modulation of the phenotype and function of Mycobacterium tuberculosisstimulated dendritic cells by adrenal steroids. Int Immunol. (2013) 25:40511. doi: 10.1093/intimm/dxt004

91. Carbone F, La Rocca C, Matarese G. Immunological functions of leptin and adiponectin. Biochimie (2012) 94:2082-8. doi: 10.1016/j.biochi.2012.05.018

92. Araghi-Niknam M, Zhang Z, Jiang S, Call O, Eskelson CD, Watson RR. Cytokine dysregulation and increased oxidation is prevented by dehydroepiandrosterone in mice infected with murine leukemia retrovirus. Proc Soc Exp Biol Med. (1997) 216:386-91. doi: 10.3181/00379727-216-44186

93. Danenberg HD, Alpert G, Lustig S, Ben-Nathan D. Dehydroepiandrosterone protects mice from endotoxin toxicity and reduces tumor necrosis factor production. Antimicrob Agents Chemother. (1992) 36:2275-9. doi: 10.1128/AAC.36.10.2275

94. Di Santo E, Foddi MC, Ricciardi-Castagnoli P, Mennini T, Ghezzi P. DHEAS inhibits TNF production in monocytes, astrocytes and microglial cells. Neuroimmunomodulation (1996) 3:285-8. doi: 10.1159/000097282

95. Di Santo E, Sironi M, Mennini T, Zinetti M, Savoldi G, Di Lorenzo D, et al. A glucocorticoid receptor-independent mechanism for neurosteroid inhibition of tumor necrosis factor production. Eur J Pharmacol. (1996) 299:179-86. doi: 10.1016/0014-2999(95)00840-3

96. Gutierrez G, Mendoza C, Zapata E, Montiel A, Reyes E, Montano LF, et al. Dehydroepiandrosterone inhibits the TNF-alpha-induced inflammatory response in human umbilical vein endothelial cells. Atherosclerosis (2007) 190:90-9. doi: 10.1016/j.atherosclerosis.2006.02.031

97. Nhamoyebonde S, Leslie A. Biological differences between the sexes and susceptibility to tuberculosis. J Infect Dis. (2014) 209(Suppl. 3):S100-6. doi: 10.1093/infdis/jiu147

98. Par G, Geli J, Kozma N, Varga P, Szekeres-Bartho J. Progesterone regulates IL12 expression in pregnancy lymphocytes by inhibiting phospholipase A2. Am J Reprod Immunol. (2003) 49:1-5. doi: 10.1034/j.1600-0897.2003. 01149.x

99. Posma E, Moes H, Heineman MJ, Faas MM. The effect of testosterone on cytokine production in the specific and non-specific immune response. Am J Reprod Immunol. (2004) 52:237-43. doi: 10.1111/j.1600-0897.2004. 00216.x

100. O'Connor MF, Motivala SJ, Valladares EM, Olmstead R, Irwin MR. Sex differences in monocyte expression of IL-6: role of autonomic mechanisms. Am J Physiol Regul Integr Comp Physiol. (2007) 293:R145-51. doi: 10.1152/ajpregu.00752.2006

101. Bouman A, Heineman MJ, Faas MM. Sex hormones and the immune response in humans. Hum Reprod Update (2005) 11:411-23. doi: 10.1093/humupd/dmi008

102. Berghofer B, Frommer T, Haley G, Fink L, Bein G, Hackstein H. TLR7 ligands induce higher IFN-alpha production in females. J Immunol. (2006) 177:2088-96. doi: 10.4049/jimmunol.177.4.2088

103. Ng MK, Nakhla S, Baoutina A, Jessup W, Handelsman DJ, Celermajer DS. Dehydroepiandrosterone, an adrenal androgen, increases human foam cell formation: a potentially pro-atherogenic effect. J Am Coll Cardiol. (2003) 42:1967-74. doi: 10.1016/j.jacc.2003.07.024

104. Kjerrulf M, Berke Z, Aspegren A, Umaerus M, Nilsson T, Svensson $\mathrm{L}$, et al. Reduced cholesterol accumulation by leptin deficient (ob/ob) mouse macrophages. Inflamm Res. (2006) 55:300-9. doi: 10.1007/s00011-006-0087-8

105. Maya-Monteiro CM, Almeida PE, D'Avila H, Martins AS, Rezende AP, Castro-Faria-Neto $\mathrm{H}$, et al. Leptin induces macrophage lipid body formation by a phosphatidylinositol 3-kinase- and mammalian target of rapamycin-dependent mechanism. J Biol Chem. (2008) 283:2203-10. doi: 10.1074/jbc.M706706200

106. Hongo S, Watanabe T, Arita S, Kanome T, Kageyama H, Shioda S, et al. Leptin modulates ACAT1 expression and cholesterol efflux from human macrophages. Am J Physiol Endocrinol Metab. (2009) 297:E474-82. doi: 10.1152/ajpendo.90369.2008

107. Wang $\mathrm{M}$, Wang D, Zhang Y, Wang X, Liu Y, Xia M. Adiponectin increases macrophage cholesterol efflux and suppresses foam cell formation in patients with type 2 diabetes mellitus. Atherosclerosis (2013) 229:62-70. doi: 10.1016/j.atherosclerosis.2013.01.017

108. McCrohon JA, Nakhla S, Jessup W, Stanley KK, Celermajer DS. Estrogen and progesterone reduce lipid accumulation in human monocytederived macrophages: a sex-specific effect. Circulation (1999) 100:2319-25. doi: 10.1161/01.CIR.100.23.2319

109. Huang CK, Pang H, Wang L, Niu Y, Luo J, Chang E, et al. New therapy via targeting androgen receptor in monocytes/macrophages to battle atherosclerosis. Hypertension (2014) 63:1345-53. doi: 10.1161/HYPERTENSIONAHA.113.02804

110. Mancuso P, Gottschalk A, Phare SM, Peters-Golden M, Lukacs NW, Huffnagle GB. Leptin-deficient mice exhibit impaired host defense in Gram-negative pneumonia. J Immunol. (2002) 168:4018-24. doi: 10.4049/jimmunol.168.8.4018

111. Baranao RI, Tenenbaum A, Rumi LS. Effects of sexual steroid hormones on the functionality of murine peritoneal macrophages. Steroids (1991) 56:481-5. doi: 10.1016/0039-128X(91)90006-H

112. Ueda K, Karas RH. Emerging evidence of the importance of rapid, nonnuclear estrogen receptor signaling in the cardiovascular system. Steroids (2013) 78:589-96. doi: 10.1016/j.steroids.2012.12.006

113. Bini EI, Mata Espinosa D, Marquina Castillo B, Barrios Payan J, Colucci $\mathrm{D}$, Cruz AF, et al. The influence of sex steroid hormones in the immunopathology of experimental pulmonary tuberculosis. PLoS ONE (2014) 9:e93831. doi: 10.1371/journal.pone.0093831

114. Dibbern J, Eggers L, Schneider BE. Sex differences in the C57BL/6 model of Mycobacterium tuberculosis infection. Sci Rep. (2017) 7:10957. doi: 10.1038/s41598-017-11438-Z

115. Vuolteenaho K, Koskinen A, Kukkonen M, Nieminen R, Paivarinta U, Moilanen T, et al. Leptin enhances synthesis of proinflammatory mediators in human osteoarthritic cartilage-mediator role of NO in leptin-induced PGE2, IL-6, and IL-8 production. Mediators Inflam. (2009) 2009:345838. doi: $10.1155 / 2009 / 345838$

116. Bongiovanni B, Mata-Espinosa D, D’Attilio L, Leon-Contreras JC, MarquezVelasco R, Bottasso O, et al. Effect of cortisol and/or DHEA on THP1derived macrophages infected with Mycobacterium tuberculosis. Tuberculosis (2015) 95:562-9. doi: 10.1016/j.tube.2015.05.011

117. Wieland CW, Florquin S, Chan ED, Leemans JC, Weijer S, Verbon A, et al. Pulmonary Mycobacterium tuberculosis infection in leptin-deficient ob/ob mice. Int Immunol. (2005) 17:1399-408. doi: 10.1093/intimm/dxh317

118. Cunningham M, Gilkeson G. Estrogen receptors in immunity and autoimmunity. Clin Rev Allergy Immunol. (2011) 40:66-73. doi: 10.1007/s12016-010-8203-5

119. Szatmari I, Gogolak P, Im JS, Dezso B, Rajnavolgyi E, Nagy L. Activation of PPARgamma specifies a dendritic cell subtype capable of enhanced induction of iNKT cell expansion. Immunity (2004) 21:95-106. doi: 10.1016/j.immuni.2004.06.003

120. Dai R, Cowan C, Heid B, Khan D, Liang Z, Pham CT, et al. Neutrophils and neutrophil serine proteases are increased in the spleens of estrogen-treated C57BL/6 mice and several strains of spontaneous lupus-prone mice. PLoS ONE (2017) 12:e0172105. doi: 10.1371/journal.pone.0172105

121. Molloy EJ, O’Neill AJ, Grantham JJ, Sheridan-Pereira M, Fitzpatrick JM, Webb DW, et al. Sex-specific alterations in neutrophil apoptosis: the role of estradiol and progesterone. Blood (2003) 102:2653-9. doi: 10.1182/blood-2003-02-0649

122. Lagranha CJ, Alba-Loureiro TC, Silva AId, Lima DDBd, Pedroza AA, Ferreira D, et al. Differences in age modulates neutrophils function. Adv Biol Chem. (2014) 4:43298. doi: 10.4236/abc.2014.41008

123. Marin DP, Bolin AP, dos Santos Rde C, Curi R, Otton R. Testosterone suppresses oxidative stress in human neutrophils. Cell Biochem Funct. (2010) 28:394-402. doi: 10.1002/cbf.1669

124. Robinson DP, Hall OJ, Nilles TL, Bream JH, Klein SL. 17beta-estradiol protects females against influenza by recruiting neutrophils and increasing virus-specific CD8 T cell responses in the lungs. J Virol. (2014) 88:4711-20. doi: 10.1128/JVI.02081-13

125. Bozza V, D’Attilio L, Didoli G, Santucci N, Nannini L, Bogue C, et al. The adrenal steroid response during tuberculosis and its effects on the mycobacterial-driven IFN-gamma production of patients and 
their household contacts. Ann N Y Acad Sci. (2009) 1153:247-55. doi: $10.1111 / j .1749-6632.2008 .03976 . x$

126. Yao Y, Li H, Ding J, Xia Y, Wang L. Progesterone impairs antigen-nonspecific immune protection by CD8 T memory cells via interferongamma gene hypermethylation. PLoS Pathog. (2017) 13:e1006736. doi: 10.1371/journal.ppat.1006736

127. Hernandez-Pando R, De La Luz Streber M, Orozco H, Arriaga K, Pavon L, Al-Nakhli SA, et al. The effects of androstenediol and dehydroepiandrosterone on the course and cytokine profile of tuberculosis in BALB/c mice. Immunology (1998) 95:234-41. doi: 10.1046/j.1365-2567.1998.00601.x

128. Hernandez-Pando R, de la Luz Streber M, Orozco H, Arriaga K, Pavon L, Marti O, et al. Emergent immunoregulatory properties of combined glucocorticoid and anti-glucocorticoid steroids in a model of tuberculosis. QJM (1998) 91:755-66. doi: 10.1093/qjmed/91.11.755

129. Hepworth MR, Hardman MJ, Grencis RK. The role of sex hormones in the development of Th2 immunity in a gender-biased model of Trichuris muris infection. Eur J Immunol. (2010) 40:406-16. doi: 10.1002/eji.2009 39589

130. Tyagi AM, Srivastava K, Mansoori MN, Trivedi R, Chattopadhyay N, Singh D. Estrogen deficiency induces the differentiation of IL-17 secreting Th17 cells: a new candidate in the pathogenesis of osteoporosis. PLoS ONE (2012) 7:e44552. doi: 10.1371/journal.pone.0044552

131. Polanczyk MJ, Carson BD, Subramanian S, Afentoulis M, Vandenbark AA, Ziegler SF, et al. Cutting edge: estrogen drives expansion of the CD4+CD25+ regulatory T cell compartment. J Immunol. (2004) 173:222730. doi: 10.4049/jimmunol.173.4.2227

132. Page ST, Plymate SR, Bremner WJ, Matsumoto AM, Hess DL, Lin DW, et al. Effect of medical castration on CD4+ CD25+ T cells, CD8+ $\mathrm{T}$ cell IFN-gamma expression, and NK cells: a physiological role for testosterone and/or its metabolites. Am J Physiol. (2006) 290:E856-63. doi: 10.1152/ajpendo.00484.2005

133. Abdullah M, Chai PS, Chong MY, Tohit ER, Ramasamy R, Pei CP, et al. Gender effect on in vitro lymphocyte subset levels of healthy individuals. Cell Immunol. (2012) 272:214-9. doi: 10.1016/j.cellimm.2011.10.009

134. Nilsson N, Carlsten H. Estrogen induces suppression of natural killer cell cytotoxicity and augmentation of polyclonal B cell activation. Cell Immunol. (1994) 158:131-9. doi: 10.1006/cimm.1994.1262

135. Lotter H, Helk E, Bernin H, Jacobs T, Prehn C, Adamski J, et al. Testosterone increases susceptibility to amebic liver abscess in mice and mediates inhibition of IFNgamma secretion in natural killer T cells. PLoS ONE (2013) 8:e55694. doi: 10.1371/journal.pone.0055694

136. Butterworth $M$, McClellan $B$, Allansmith $M$. Influence of sex in immunoglobulin levels. Nature (1967) 214:1224-5. doi: 10.1038/2141 $224 \mathrm{a} 0$

137. McMurray RW, Suwannaroj S, Ndebele K, Jenkins JK. Differential effects of sex steroids on $\mathrm{T}$ and $\mathrm{B}$ cells: modulation of cell cycle phase distribution, apoptosis and bcl-2 protein levels. Pathobiology (2001) 69:4458. doi: 10.1159/000048757

138. Yao G, Liang J, Han X, Hou Y. In vivo modulation of the circulating lymphocyte subsets and monocytes by androgen. Int Immunopharmacol. (2003) 3:1853-60. doi: 10.1016/j.intimp.2003.09.002

139. Klein SL, Jedlicka A, Pekosz A. The Xs and Y of immune responses to viral vaccines. Lancet Infect Dis. (2010) 10:338-49. doi: 10.1016/S1473-3099(10)70049-9

140. Roved J, Westerdahl H, Hasselquist D. Sex differences in immune responses: hormonal effects, antagonistic selection, and evolutionary consequences. Horm Behav. (2017) 88:95-105. doi: 10.1016/j.yhbeh.2016.11.017

141. Jentsch-Ullrich K, Koenigsmann M, Mohren M, Franke A. Lymphocyte subsets' reference ranges in an age- and gender-balanced population of 100 healthy adults-a monocentric German study. Clin Immunol. (2005) 116:192-7. doi: 10.1016/j.clim.2005.03.020

142. Amadori A, Zamarchi R, De Silvestro G, Forza G, Cavatton G, Danieli GA, et al. Genetic control of the CD4/CD8 T-cell ratio in humans. Nat Med. (1995) 1:1279-83. doi: 10.1038/nm1295-1279

143. Lu LL, Chung AW, Rosebrock TR, Ghebremichael M, Yu WH, Grace PS, et al. A functional role for antibodies in tuberculosis. Cell (2016) 167:433-43 e14. doi: $10.1016 /$ j.cell.2016.08.072
144. Neyrolles O, Quintana-Murci L. Sexual inequality in tuberculosis. PLoS Med. (2009) 6:e1000199. doi: 10.1371/journal.pmed.1000199

145. Horstman AM, Dillon EL, Urban RJ, Sheffield-Moore M. The role of androgens and estrogens on healthy aging and longevity. J Gerontol A Biol Sci Med Sci. (2012) 67:1140-52. doi: 10.1093/gerona/gls068

146. Mouritsen A, Aksglaede L, Soerensen K, Hagen CP, Petersen JH, Main KM, et al. The pubertal transition in 179 healthy Danish children: associations between pubarche, adrenarche, gonadarche, and body composition. Eur J Endocrinol. (2013) 168:129-36. doi: 10.1530/EJE-12-0191

147. Guran T, Firat I, Yildiz F, Kaplan Bulut I, Dogru M, Bereket A. Reference values for serum dehydroepiandrosterone-sulphate in healthy children and adolescents with emphasis on the age of adrenarche and pubarche. Clin Endocrinol. (2015) 82:712-8. doi: 10.1111/cen.12612

148. Isidori AM, Strollo F, More M, Caprio M, Aversa A, Moretti C, et al. Leptin and aging: correlation with endocrine changes in male and female healthy adult populations of different body weights. J Clin Endocrinol Metab. (2000) 85:1954-62. doi: 10.1210/jcem.85.5.6572

149. Casadevall A, Pirofski LA. The damage-response framework of microbial pathogenesis. Nat Rev Microbiol. (2003) 1:17-24. doi: 10.1038/ nrmicro732

150. Jacobson DL, Gange SJ, Rose NR, Graham NM. Epidemiology and estimated population burden of selected autoimmune diseases in the United States. Clin Immunol Immunopathol. (1997) 84:223-43. doi: 10.1006/clin. 1997.4412

151. Portevin D, Gagneux S, Comas I, Young D. Human macrophage responses to clinical isolates from the Mycobacterium tuberculosis complex discriminate between ancient and modern lineages. PLoS Pathog. (2011) 7:e1001307. doi: 10.1371/journal.ppat.1001307

152. Holt KE, McAdam P, Thai PVK, Thuong NTT, Ha DTM, Lan NN, et al. Frequent transmission of the Mycobacterium tuberculosis Beijing lineage and positive selection for the EsxW Beijing variant in Vietnam. Nat Genet. (2018) 50:849-56. doi: 10.1038/s41588-018-0117-9

153. Pinheiro I, Dejager L, Libert C. X-chromosome-located microRNAs in immunity: might they explain male/female differences? The $\mathrm{X}$ chromosomegenomic context may affect X-located miRNAs and downstream signaling, thereby contributing to the enhanced immune response of females. Bioessays (2011) 33:791-802. doi: 10.1002/bies.201100047

154. Meier A, Chang JJ, Chan ES, Pollard RB, Sidhu HK, Kulkarni S, et al. Sex differences in the Toll-like receptor-mediated response of plasmacytoid dendritic cells to HIV-1. Nat Med. (2009) 15:955-9. doi: 10.1038/ nm.2004

155. Moreira-Teixeira L, Mayer-Barber K, Sher A, O'Garra A. Type I interferons in tuberculosis: foe and occasionally friend. J Exp Med. (2018) 215:1273-85. doi: 10.1084/jem.20180325

156. Mayer-Barber KD, Andrade BB, Oland SD, Amaral EP, Barber DL, Gonzales J, et al. Host-directed therapy of tuberculosis based on interleukin-1 and type I interferon crosstalk. Nature (2014) 511:99-103. doi: 10.1038/nature 13489

157. Torcia MG, Nencioni L, Clemente AM, Civitelli L, Celestino I, Limongi D, et al. Sex differences in the response to viral infections: TLR8 and TLR9 ligand stimulation induce higher IL10 production in males. PLoS ONE (2012) 7:e39853. doi: 10.1371/journal.pone.0039853

158. Aomatsu M, Kato T, Kasahara E, Kitagawa S. Gender difference in tumor necrosis factor-alpha production in human neutrophils stimulated by lipopolysaccharide and interferon-gamma. Biochem Biophys Res Commun. (2013) 441:220-5. doi: 10.1016/j.bbrc.2013.10.042

159. Ecker S, Chen L, Pancaldi V, Bagger FO, Fernandez JM, Carrillo de Santa Pau E, et al. Genome-wide analysis of differential transcriptional and epigenetic variability across human immune cell types. Genome Biol. (2017) 18:18. doi: 10.1186/s13059-017-1156-8

160. Esmail H, Lai RP, Lesosky M, Wilkinson KA, Graham CM, Horswell S, et al. Complement pathway gene activation and rising circulating immune complexes characterize early disease in HIV-associated tuberculosis. Proc Natl Acad Sci USA. (2018) 115:E964-73. doi: 10.1073/pnas.1711853115

161. Bloom CI, Graham CM, Berry MP, Rozakeas F, Redford PS, Wang Y, et al. Transcriptional blood signatures distinguish pulmonary tuberculosis, pulmonary sarcoidosis, pneumonias and lung cancers. PLOS ONE (2013) 8:e70630. doi: 10.1371/journal.pone.0070630 
162. Zak DE, Penn-Nicholson A, Scriba TJ, Thompson E, Suliman S, Amon LM, et al. A blood RNA signature for tuberculosis disease risk: a prospective cohort study. Lancet (2016) 387:2312-22. doi: 10.1016/S0140-6736(15)01316-1

163. Kutlu NO, Akinci A, Sonmezgoz E, Temel I, Evliyaoglu E. The effects of androstenediol and dehydroepiandrosterone on the immune response to BCG at puberty. J Trop Pediatr. (2003) 49:181-5. doi: 10.1093/tropej/49.3.181

164. Izzo RA, Cicardo VH. Gonads and experimental tuberculosis. Nature (1947) 159:155. doi: 10.1038/160155a0

165. Yamamoto Y, Saito H, Setogawa T, Tomioka H. Sex differences in host resistance to Mycobacterium marinum infection in mice. Infect Immun. (1991) 59:4089-96.

166. Yamamoto Y, Tomioka H, Sato K, Saito H, Yamada Y, Setogawa T. Sex differences in the susceptibility of mice to infection induced by Mycobacterium intracellulare. Am Rev Respir Dis. (1990) 142:430-3. doi: 10.1164/ajrccm/142.2.430

167. Tsuyuguchi K, Suzuki K, Matsumoto H, Tanaka E, Amitani R, Kuze F. Effect of oestrogen on Mycobacterium avium complex pulmonary infection in mice. Clin Exp Immunol. (2001) 123:428-34. doi: 10.1046/j.1365-2249.2001.01474.x

168. Scalerandi MV, Peinetti N, Leimgruber C, Cuello Rubio MM, Nicola JP, Menezes GB, et al. Inefficient N2-like neutrophils are promoted by androgens during infection. Front Immunol. (2018) 9:1980. doi: 10.3389/fimmu.2018.01980

169. Lee RS, Proulx JF, Menzies D, Behr MA. Progression to tuberculosis disease increases with multiple exposures. Eur Respir J. (2016) 48:1682-9. doi: 10.1183/13993003.00893-2016

170. Urbanowski ME, Ihms EA, Bigelow K, Kubler A, Elkington PT, Bishai WR. Repetitive aerosol exposure promotes cavitary tuberculosis and enables screening for targeted inhibitors of extensive lung destruction. J Infect Dis. (2018) 218:53-63. doi: 10.1093/infdis/jiy127

171. Patton GC, Sawyer SM, Santelli JS, Ross DA, Afifi R, Allen NB, et al. Our future: a Lancet commission on adolescent health and wellbeing. Lancet (2016) 387:2423-78. doi: 10.1016/S0140-6736(16)00579-1

172. Mossong J, Hens N, Jit M, Beutels P, Auranen K, Mikolajczyk R, et al. Social contacts and mixing patterns relevant to the spread of infectious diseases. PLoS Med. (2008) 5:e74. doi: 10.1371/journal.pmed.0050074

173. Johnstone-Robertson SP, Mark D, Morrow C, Middelkoop K, Chiswell M, Aquino LD, et al. Social mixing patterns within a South African township community: implications for respiratory disease transmission and control. Am J Epidemiol. (2011) 174:1246-55. doi: 10.1093/aje/kwr251

174. Wood R, Racow K, Bekker LG, Morrow C, Middelkoop K, Mark D, et al. Indoor social networks in a South African township: potential contribution of location to tuberculosis transmission. PLOS ONE (2012) 7:e39246. doi: 10.1371/journal.pone.0039246

175. Grijalva CG, Goeyvaerts N, Verastegui H, Edwards KM, Gil AI, Lanata CF, et al. A household-based study of contact networks relevant for the spread of infectious diseases in the highlands of Peru. PLoS ONE (2015) 10:e0118457. doi: 10.1371/journal.pone.0118457

176. Ajelli M, Litvinova M. Estimating contact patterns relevant to the spread of infectious diseases in Russia. J Theor Biol. (2017) 419:1-7. doi: 10.1016/j.jtbi.2017.01.041

177. Madico G, Gilman RH, Checkley W, Cabrera L, Kohlstadt I, Kacena K, et al. Community infection ratio as an indicator for tuberculosis control. Lancet (1995) 345:416-9. doi: 10.1016/S0140-6736(95)90401-8

178. Martinez L, Shen Y, Mupere E, Kizza A, Hill PC, Whalen CC. Transmission of Mycobacterium tuberculosis in households and the community: a systematic review and meta-analysis. Am J Epidemiol. (2017) 185:1327-39. doi: 10.1093/aje/kwx025

179. Lonnroth K, Williams BG, Stadlin S, Jaramillo E, Dye C. Alcohol use as a risk factor for tuberculosis - a systematic review. BMC Public Health (2008) 8:289. doi: 10.1186/1471-2458-8-289

180. Lin HH, Ezzati M, Murray M. Tobacco smoke, indoor air pollution and tuberculosis: a systematic review and meta-analysis. PLoS Med. (2007) 4:e20. doi: 10.1371/journal.pmed.0040020

181. Deiss RG, Rodwell TC, Garfein RS. Tuberculosis and illicit drug use: review and update. Clin Infect Dis. (2009) 48:72-82. doi: 10.1086/ 594126
182. Kiboi NG, Nebere SN, Karanja JK. Immunological interactions of tuberculosis with drugs and substance use: a systematic review and update. J Pul Respir Med. (2016) 6:326. doi: 10.4172/2161-105X.10 00326

183. Mathad JS, Gupta A. Tuberculosis in pregnant and postpartum women: epidemiology, management, and research gaps. Clin Infect Dis. (2012) 55:1532-49. doi: 10.1093/cid/cis732

184. Bates M, Ahmed Y, Kapata N, Maeurer M, Mwaba P, Zumla A. Perspectives on tuberculosis in pregnancy. Int J Infect Dis. (2015) 32:124-7. doi: 10.1016/j.ijid.2014.12.014

185. UNAIDS. Ending AIDS: Progress Towards the 90-90-90 Targets (2017). Available online at: http://www.unaids.org/sites/default/files/media_asset/ Global_AIDS_update_2017 (Accessed June 27, 2018).

186. Idele P, Gillespie A, Porth T, Suzuki C, Mahy M, Kasedde S, et al. Epidemiology of HIV and AIDS among adolescents: current status, inequities, and data gaps. J Acquir Immune Defic Syndr. (2014) 66(Suppl. 2):S144-53. doi: 10.1097/QAI.0000000000000176

187. Dodd PJ, Prendergast AJ, Beecroft C, Kampmann B, Seddon JA. The impact of HIV and antiretroviral therapy on TB risk in children: a systematic review and meta-analysis. Thorax (2017) 72:559-75. doi: 10.1136/thoraxjnl-2016-209421

188. Getahun H, Gunneberg C, Granich R, Nunn P. HIV infection-associated tuberculosis: the epidemiology and the response. Clin Infect Dis. (2010) 50(Suppl. 3):S201-7. doi: 10.1086/651492

189. Marston M, Becquet R, Zaba B, Moulton LH, Gray G, Coovadia H, et al. Net survival of perinatally and postnatally HIV-infected children: a pooled analysis of individual data from sub-Saharan Africa. Int J Epidemiol. (2011) 40:385-96. doi: 10.1093/ije/dyq255

190. UNAIDS. Topic: Data. Available online at: www.unaids.org/en/topic/data (Accessed June 27, 2018).

191. Cobelens F, Nagelkerke N, Fletcher H. The convergent epidemiology of tuberculosis and human cytomegalovirus infection. F1000Res. (2018) 7:280. doi: 10.12688/f1000research.14184.2

192. Miles DJ, van der Sande M, Jeffries D, Kaye S, Ismaili J, Ojuola O, et al. Cytomegalovirus infection in Gambian infants leads to profound CD8 T-cell differentiation. J Virol. (2007) 81:5766-76. doi: 10.1128/JVI.00 052-07

193. Muller J, Matsumiya M, Snowden MA, Landry B, Satti I, Harris SA, et al. Cytomegalovirus infection is a risk factor for TB disease in Infants. bioRxiv[Preprint] (2017). doi: 10.1101/222646

194. Dangor Z, Izu A, Moore DP, Nunes MC, Solomon F, Beylis N, et al. Temporal association in hospitalizations for tuberculosis, invasive pneumococcal disease and influenza virus illness in South African children. PLoS ONE (2014) 9:e91464. doi: 10.1371/journal.pone.0091464

195. Fares A. Seasonality of tuberculosis. J Glob Infect Dis. (2011) 3:46-55. doi: 10.4103/0974-777X.77296

196. Luo T, Sumi A, Zhou D, Kobayashi N, Mise K, Yu B, et al. Seasonality of reported tuberculosis cases from 2006 to 2010 in Wuhan, China. Epidemiol Infect. (2014) 142:2036-48. doi: 10.1017/S09502688130 03142

197. Espersen E. Epidemic of influenza B among Greenlandic patients in a Danish tuberculosis sanatorium; influenza and pulmonary tuberculosis. Acta Tuberc Scand. (1954) 29:125-39.

198. Walaza S, Cohen C, Nanoo A, Cohen AL, McAnerney J, von Mollendorf $\mathrm{C}$, et al. Excess mortality associated with influenza among tuberculosis deaths in South Africa, 1999-2009. PLoS ONE (2015) 10:e0129173. doi: 10.1371/journal.pone.0129173

199. Zurcher K, Zwahlen M, Ballif M, Rieder HL, Egger M, Fenner L. Influenza pandemics and tuberculosis mortality in 1889 and 1918: Analysis of historical data from Switzerland. PLoS ONE (2016) 11:e0162575. doi: 10.1371/journal.pone.0162575

200. Oei W, Nishiura $H$. The relationship between tuberculosis and influenza death during the influenza (H1N1) pandemic from 1918-19. Comput Math Methods Med. (2012) 2012:124861. doi: 10.1155/2012/ 124861

201. Fox TG, Christenson JC. Influenza and parainfluenza viral infections in children. Pediatr Rev. (2014) 35:217-27; quiz 28. doi: 10.1542/pir. 35-6-217 
202. Enwere GC, Ota MO, Obaro SK. The host response in malaria and depression of defence against tuberculosis. Ann Trop Med Parasitol. (1999) 93:669-78. doi: 10.1080/00034983.1999.11813470

203. Babu S, Nutman TB. Helminth-tuberculosis co-infection: an immunologic perspective. Trends Immunol. (2016) 37:597-607. doi: 10.1016/j.it.2016.07.005

204. Deroost K, Pham TT, Opdenakker G, Van den Steen PE. The immunological balance between host and parasite in malaria. FEMS Microbiol Rev. (2016) 40:208-57. doi: 10.1093/femsre/fuv046

205. Maizels RM, McSorley HJ. Regulation of the host immune system by helminth parasites. J Allergy Clin Immunol. (2016) 138:666-75. doi: 10.1016/j.jaci.2016.07.007

206. Van Der Meeren O, Hatherill M, Nduba V, Wilkinson RJ, Muyoyeta M, Van Brakel E, et al. Phase $2 b$ controlled trial of M72/AS01E vaccine to prevent tuberculosis. N Engl J Med. (2018) 379:1621-34. doi: 10.1056/NEJMoa1803484
Conflict of Interest Statement: The authors declare that the research was conducted in the absence of any commercial or financial relationships that could be construed as a potential conflict of interest.

The handling editor is currently co-organizing a Research Topic with one of the authors AC, and confirms the absence of any other collaboration. The reviewer SG declared a shared affiliation, though no other collaboration, with one of the authors SC to the handling Editor.

Copyright (c) 2018 Seddon, Chiang, Esmail and Coussens. This is an open-access article distributed under the terms of the Creative Commons Attribution License (CC $B Y)$. The use, distribution or reproduction in other forums is permitted, provided the original author(s) and the copyright owner(s) are credited and that the original publication in this journal is cited, in accordance with accepted academic practice. No use, distribution or reproduction is permitted which does not comply with these terms. 